Guillebead: Studien über Milchfehler und Euterentzündungen pei Rindern und Ziegen. Landw. Jahrb. d. Schweiz, 4. Bd., S. 27. 1890.

HAMmer, B. W. and M. P. BAKER: Studies on the Streptococcus paracitrovorus group. Abstr. Bact., Vol. 13, p. 12. 1927.

KRUSE, W.: Das Verhältnis der Milchsäurebakterien zum Streptococcus lanceolatus. Zentralbl. f. Bakt., I. Abt., Orig., 34. Bd., S. 737. 1903. - KULP, W. L. and L. F. RetTGER: Comparative study of Lactobacillus acidophilus and L. bulgaricus. Journ. Bact., Vol. 9, p. 357. 1924.

Leichmann, G.: Über die freiwillige Säuerung der Milch. Milchztg., 23. Bd., S. 523. 1894. - LöHNIs, F. (1): Handbuch der landwirtschaftlichen Bakteriologie. Berlin: Gebr. Borntraeger. 1910. - (2): Untersuchungen über den Keimgehalt der in Leipzig im Handel befindlichen Milchsorten. Milchw. Zentralbl., 43. Bd., S. 9. 1914. - (3): Untersuchungen über das vorzeitige Gerinnen der Milch an Gewittertagen. Molk. Ztg. (Hildesheim), 28. Bd., S. 785. 1914. - (4): Der Verbrauch von roher und von erhitzter Milch in Deutschland und in Amerika. Südd. Molk. Ztg., 47. Bd., S. 1145. 1926. - Lux, A.: Über den Gehalt der frischgemolkenen Milch an Bakterien. Zentralbl. f. Bakt., II. Abt., 11. Bd., S. 275.1903.

Orla-Jensen, S.: The lactic acid bacteria. Mém. Acad. d. sci. Copenhague, Sect. d. sciences, 8. Sér. T. 5, no. 2. 1919.

Pusch, G.: Die Kindermilchproduktion in wirtschaftlicher und hygienischer Beleuchtung usw. Zeitschr. f. Infektionskrankh. d. Haustiere, 3. Bd., S. 439. 1908.

Rodenkirchen, J.: Der Einfluß von Erhitzung und Aufbewahrung auf den Keimgehalt und die Haltbarkeit der Milch. Milchw. Forsch., 6. Bd., Orig., S. 65. 1928.

Schröter, O.: Vergleichende Prüfung bakteriologischer und biochemischer Methoden zur Beurteilung der Milch. Zentralbl. f. Bakt., II. Abt., 32. Bd., S. 181. 1912. - Schulz, L.: Über den Schmutzgehalt der Würzburger Marktmilch und die Herkunft der Milchbakterien. Arch. f. Hyg., 14. Bd., S. 260. 1892. - STECK, W.: Untersuchungen über die bakterielle Besiedlung normaler Kuheuter. Landw. Jahrb. d. Schweiz, S. 511. 1921.

UHL: Untersuchungen der Marktmilch in Gießen. Zeitschr. f. Hyg., 12. Bd., S. 479.1892.

WinkLer, W.: Wie kann die Milch haltbar gemacht werden? Österr. Molk. Ztg., 15. Bd., S. 129. 1908.

\title{
3. Pathogene Bakterien, die gelegentlich in der Milch vorkommen
}

\author{
Von \\ W. Ernst-München \\ A. Bakterien vom Menschen
}

Pathogene, für den Menschen oder das Tier oder beide krankmachende Keime können auf verschiedenstem Weg in die Milch gelangen. Sie kommen entweder aus infizierten oder kranken Tieren oder Eutern, von kranken Menschen oder solchen, die Bazillenträger sind, ohne krank zu sein, oder sie können sonst aus der Umwelt gelegentlich der Milchgewinnung und -zurichtung, der weiteren Herstellung, des Transportes und des Verschleißes oder im Haushalt des Konsumenten in die Milch gelangen. Auch Krankenpersonal trägt zur Infektion der Milch gelegentlich bei. In der Milch selbst können sich die Krankheitserreger zum mindesten in der ersten und zweiten Phase der Milchzerlegung nach KonING gut halten oder sie können sich unter Umständen sogar vermehren. Von den Erregern, die hier eine Rolle spielen und die vom Menschen stammen, seien kurz erwähnt die Typhusbazillen, die Ruhrerreger, die Paratyphusbazillen, Diphtheriebazillen, Scharlacherreger und Menschentuberkelbazillen. 
Nach Wedemann kann die spontane Säuerung der Milch gefährlich werden, weil innerhalb der Zeit, in der die Säurebildung vor sich geht, auch pathogene Keime sich entwickeln können. In Kaseinflocken entziehen sie sich nicht selten der Milchsäureeinwirkung. Demnach ist mit einer Keimvernichtung bei der gewöhnlichen Aufbewahrungsdauer nicht zu rechnen. Tuberkelbazillen bleiben bis 18 Tage ohne Schwächung am Leben. Typhusbazillen können tagelang trotz hoher Säuerung überdauern.

Die praktische Marktmilchuntersuchung wird kaum in die Lage kommen, auf derartige Krankheitserreger untersuchen zu müssen, das ist Sache der hygienischen Institute und der bakteriologischen Untersuchungsanstalten. Der Verdacht, daß Milch die Überträgerin ist, wird erweckt, wenn unter den Hauptmilchkonsumenten, den Frauen, Dienstmädchen und Kindern, gleichzeitig vermehrte Krankheitsfälle auftreten. Man spricht dann von Milchepidemien, das sind Massenerkrankungen, die durch Milchgenuß verbreitet werden. Plötzlich, explosionsartig, treten solche Erkrankungen bei Konsumenten von Milch einer bestimmten Herkunft auf.

Wird die in Frage kommende Milch ausreichend erhitzt oder die Bezugsquelle geschlossen, dann steht die Seuche. Auch bei der Dauererhitzung (30' bei $63^{\circ} \mathrm{C}$ ) gehen die meisten Typhus- und Paratyphusstämme zugrunde. Einige Male wurde ein Überleben festgestellt (SEelemann).

Am häufigsten sind unter solchen Milchepidemien Typhuserkrankungen. Solche sind zusammengestellt von Schüder, Rosenau, LuMsden und Castle, Trask, Kosser, Forster, Scheller und anderen. Dabei üben nicht selten die Fliegen, die an den Entleerungen Typhuskranker saugen und an Milchgefäße auffliegen, die infizierende vermittelnde Rolle. Fliegen, die Typhusbazillen aufgenommen haben, können solche noch nach 23 Tagen in lebensfähigem Zustand enthalten (Frcker). Gewöhnlich werden aber die Typhusbazillen durch Bazillenträger oder nur leicht erkrankte Personen oder Rekonvaleszenten beim Melkgeschäft oder anderen Hantierungen im Milchverkehr oder in Molkereien, durch Milchhändler oder Krankenpfleger der Milch oder den Milchspeisen zugeführt. Besonders gefährlich wirken sich dabei Dauerausscheider von Typhusbazillen aus, die wie Kossec lehrreich beweist, jahrelang zu Typhusausbrüchen in entfernten Milchversorgungsgebieten Anlaß geben können. Nach dem Wasser spielt die Milch die Hauptrolle bei der Typhusverbreitung (v. Drigalski). Neben den infizierten Händen ist das Spülwasser oder bei Fälschungen der Wasserzusatz die Quelle der Milchinfektion. Auch ungereinigte Milchflaschen, die aus Krankenstuben zurückkommen, spielen eine Rolle. Vielleicht kommt auch die Einstreu von Bettstroh in Betracht. In Sammelmolkereien werden Milchmengen weiterer Produzenten mit der gefährlichen Milch vermischt, große Mengen Milch infiziert, die Magermilch davon an zahlreiche Produzenten zurückgesandt. Unter solchen Verhältnissen erklärt sich das explosionsartige Aufflammen von Milchepidemien. In roher Milch können sich Typhuskeime vermehren (HЕIM), in Sauermilch und Kefir, in Buttermilch bleiben sie meist nur 1 bis 3 Tage am Leben. Zunehmende Säuerung zerstört die Typhuskeime gewöhnlich (HEIM, BRokrs, Fraenkel und Küster). Andere Autoren, wie Bolley und Field, Bruck, Cantley, haben trotz Säuerung und Gerinnung die zugesetzten Keime noch nach $5,7,10,11,13,21$ und 35 Tagen lebend und vermehrungsfähig gefunden.

In Süßrahmbutter halten sie sich 3 bis 4 Wochen lebensfähig. Neben Kolikeimen hat FIoRIANi aus fehlerhafter Butter, die Wasser eines Berieselungsgrabens enthielt, Typhuskeime nachgewiesen. Talaufwärts lag an dem Graben ein Spital, das Typhuskranke beherbergte. 
In sterilisierter Milch wächst Bacillus typhi, ohne die Milch zur Gerinnung zu bringen. Auch in roher Milch wachsen Typhusbazillen vorzüglich.

Der Versuch, Typhusbazillen in Milch, die Veranlassung zur Seuchenverbreitung gab, nachzuweisen, mißlingt sehr häufig, einmal weil die Untersuchung im Vergleich zur Ansteckung stets sehr spät erfolgt (es handelt sich bei der Untersuchung zwar um Milch gleicher Herkunft, aber nicht mehr um die gleiche Milch; das Personal kann gewechselt haben. Die Bakterienausscheidung wechselt bei den in Frage stehenden Personen). Zum Nachweis dienen Rahm und Zentrifugenbodensatz. Die Bakterien werden in Heuinfus, Galle oder Gallenährböden oder Lösungen von Nutrose und Koffein und Kristallviolett elektiv angereichert und dann auf den bekannten Spezialnährböden nach ENDo, DRIGALSKI und CoNRADI, auf Malachitgrünagar usw. ausgesät.

Den Gegensatz, der zwischen den nicht seltenen Übertragungen von Typhus durch Milch und der Zahl der gelungenen Nachweise des Bazillus in der in Frage kommenden Ausgangsmilch besteht, suchte WoHLFEIL durch eine Auswahlmethode auszugleichen, die in der Milch schon die Wucherung der übrigen Bakterien, insbesondere des Bacterium coli, zurückdrängt. Er mischte $7,5 \mathrm{~cm}^{3}$ Milch mit $2,5 \mathrm{~cm}^{3}$ Koffeinbouillon $(1,2 \%)$ und alkalisierte bis zur deutlichen Rotfärbung (Phenolphthalein) mit 10\% Sodalösung. Nach 4 bis 7 Stunden wird auf Endoplatten usw. ausgestrichen.

Paratyphus-B-Bazillen sollen in Milch gefunden worden sein, auch sind Paratyphusfälle beim Menschen beobachtet worden, die auf Milch, Sahne oder Milchspeisen (Vanilletorte) zurückgeführt wurden. Bacillus enteritidis GäRTNER und Bacillus enteritidis BRESLAU werden in Milchproben wohl mitunter und häufiger enthalten sein als der Bacillus Paratyphus B. KuEIN hat den Bacillus GÄRTNER in 10 von 39 Proben verschiedener englischer Farmen nachgewiesen, Aumann fand ihn in 279 Proben nie. HüBener hat bei 70 Marktmilchproben in 7 Paratyphusbazillen gefunden.

Parakolibazillen, Bacillus enteritidis GÄRTNER, Bacterium coli variet. dysentericum sind in Milch, Milchspeisen, in Käse, Quarg, Knetkäse, weniger in Butter, gefunden worden (W. Türk, Jensen, Fonteyne, Holst, BerG, HüBENER). Infektionen sind mehrfach beobachtet worden (v. VAGEDES, Fischer, Nielsen, Gram und anderen).

Bei diesen Bakterien der Koli-Typhusreihe werden neuere Forschungen erst den Beweis erbringen müssen, welchen Anteil an Milchepidemien der echte Bacillus paratyphi-B-ScHотTмüLLER nimmt, der bekanntlich bei Tieren nicht oder höchstens sehr selten vorkommt, und welchen der Bacillus enteritidis BRESLAU hat, ferner wie oft echte GärTnER-Stämme und endlich wie oft andere, abtrennbare Typen vorkommen, die im Darm von gesunden Milchkühen gefunden werden können und gelegentlich auch als Blutvergifter bei Tieren auftreten oder bei örtlichen Leiden (hochakuten Mastitiden, akuten Darmentzündungen, Tragsackentzündungen) der Rinder gefunden wurden. Besonderes Augenmerk ist dabei auf die Ställe zu richten, in denen Kälberruhr und Kälberlähme herrschen, oder Todesfälle und Notschlachtungen vorkommen, bei denen die folgende Zerlegung oder Fleischbeschau keine oder keine wesentlichen Veränderungen ergaben.

\section{Dysenteriebazillen}

Ruhrbazillen, und zwar sowohl die des Typus SHiga-Kruse wie auch die Pseudodysenteriebazillen FLEXNER sind mehrfach bei Säuglingen gefunden worden (Jehle, Wollstein, Hastings, Pease und Shaw, Anche und Campana, 
Sommerfeld). Die Bazillen dieser Gruppe gehen in gewöhnlicher Milch nach deren Säuerung erst in etwa 8 Tagen zugrunde. Ähnlich ist ihr Verhalten in Butter und Käse (E. PFUHL).

In steriler Milch bildet der Typus SHIGA-KRuse etwas Säure, ohne die Milch zu koagulieren.

\section{Cholerabazillen}

Sommerfeld zitiert mehrere Fälle, in denen Cholera höchstwahrscheinlich durch Milch übertragen wurde. Diese Fälle sind von GAFFky, Simpson und KNÜPPEL studiert und dabei ist unter anderem nachgewiesen worden, daß die in Frage kommende Milch mit Wasser verdünnt war, in einem Falle mit Wasser aus einem Behälter, in den die Entleerungen eines Cholerakranken geraten waren. Auch durch Butter kann Cholera übertragen werden, obwohl die Choleravibrionen sich im allgemeinen schlecht in Butter halten (HEIM: gewöhnlich nicht länger als 1 Tag, CunNIngham: nicht 24 Stunden, FrIEdrich: 1 bis 2 Tage, LaSER: 5 bis 8 Tage, Rowland: nur wenige Tage, HeIm: 1 bis 2 Tage, 1 Fall bis 49 Tage). Nach KItasato tötet starke Säurebildung sie ab. Frische Butter enthält sie länger, bis zu 1 Woche (ScHRANK), ranzige tötet sie rasch ab.

In Käse, der aus Milch, der Cholerabazillen zugemischt waren, hergestellt wurde, fanden sich schon 9 Stunden später keine mehr (WEIGManN und ZIRN).

In sterilisierter Milch wachsen Cholerabazillen unter geringer Säurebildung mit oder ohne schwache Koagulation. Rohe, keimarme Milch tötet sie ab (HEsse, KOLLE).

\section{Diphtheriebazillen}

Diphtheriebazillen wachsen in sterilisierter und roher Milch (falls sie zur Zeit der Infektion noch keimarm war) gut (SchotTelius, Ellerhorst, Eyre, Feinberg, Montefusco, Jensen, Escherich, Beck, Zarniko). Dabei scheint es auf die Temperatur anzukommen. KLEIN fand gute Vermehrung bei $20^{\circ} \mathrm{C}$, keine bei $37^{\circ} \mathrm{C}$. Der Säuerung widerstehen sie nach JENsEn, doch gehen sie in roher Buttermilch innerhalb 24 Stunden zugrunde, es sei denn, daß größere Mengen eingebracht wurden. Milchepidemien sind beobachtet. EyRE hat Diphtheriebazillen aus Milch unter Verwendung des Rahmes züchten können. In der durch solche Milch beliefertèn Schule kamen Diphtheriefälle vor.

In der Milch kommen häufig Pseudodiphtheriebazillen vor. Bacillus pyogenes crassus z. B. ist sehr diphtheriebazillenähnlich, er scheint identisch mit dem Corynebacillus pyelonephritidis bovis und weit verbreiteten Bakterientypen zuzugehören. Eine besondere Rolle scheint die Milch bei der Verbreitung der Diphtherie nicht zu spielen.

\section{Scharlach}

Scharlacherreger sollen ebenfalls mit Milch Verbreitung gefunden haben (Trask, Sieveking).

\section{Andere Krankheitskeime}

Mehr oder weniger gut wachsen andere Bazillen in Milch, z. B. Pestbazillen in sterilisierter Milch langsam; Pneumokokken lassen die Milch gerinnen, Meningokokken wachsen schlecht, Säurebildung unterdrückt sie; der Bazillus der Pseudotuberkulose der Nagetiere wächst gut, ebenso der Bazillus des blaugrünen Eiters, ferner Tetanusbazillen, Bazillus des malignen Ödems. 


\section{Bacterium coli.}

Die Zugehörigen des Kolitypus (Escherich) wachsen in roher und sterilisierter Milch ausgezeichnet. Sie bilden Milchsäure; die Milch gerinnt; die Gasbildung ist bei echten Kolistämmen stets vorhanden. Sie sind in frisch ermolkener Milch wenig, dagegen häufig nach 24stündiger Aufbewahrung gefunden worden (Hunter). Sie vermehren sich besonders bei 37 bis $40^{\circ} \mathrm{C}$. Ihr Fund ist ohne Bedeutung, zeigt aber geringe Stallreinlichkeit an. Sie gehören zu den gewöhnlichen Dickdarmbewohnern des Menschen und der Tiere.

Nach KIтт gehört der Bacillus phlegmasiae uberis zur Koligruppe.

\section{B. Krankheitserreger vom Tiere}

Bei Tierkrankheiten können Bakterien in die Milch unmittelbar übergehen, z. B. bei Euterleiden, oder mit der Milch ausgeschieden werden oder bei Darmoder Tragsackleiden beim Melken mit dem Melkschmutz in die Milch gelangen.

Besonderes Interesse haben:

\section{Milzbrand}

Nach v. OsteRtag vermögen die Auskleidungen der Euterdrüschen und das unversehrte Endothel der Haargefäße den Übertritt von Milzbrandbazillen aus dem Gefäßstrom in die Milchwege abzuhalten. Wenn aber Blutungen im Euter auftreten, dann dringen auch Milzbrandbazillen in die Milch ein und werden mit ihr ermolken. Der Autor konnte bei 20 an Milzbrand leidenden Kühen $1 \mathrm{mal}$ unter angegebenen Umständen Bazillen nachweisen. Ebenso gelang der Nachweis von Milzbrandbazillen Bolutnger, Chambreluent und Mousous, Feser und Monatzkow. M. Fadyean fand in Milch, die nach dem Tode von Milzbrandtieren ermolken war, in einigen Fällen Milzbrandkeime. Die Milch kranker und verdächtiger Tiere ist unschädlich zu beseitigen. Durch tägliche Temperaturmessung findet man erkrankende Tiere früh genug heraus, um mit Sicherheit den Übergang von Bazillen in die Milch auszuschließen. M. Fadyean hält den Übergang erst einige Stunden vor dem Tode für möglich.

In der Milch vermehren sich die Milzbrandkeime nur die ersten 3 Stunden. Dieser Vermehrung folgt in 18 bis 24 Stunden die Bazillenvernichtung (CARo). Sporen bleiben allerdings auch bei Säuerung der Milch am Leben (INGHILLERI). Sterile Milch ist ein guter Nährboden für Anthraxbazillen. Die Milch gerinnt dabei unter Einwirkung des Bakterienlabs, das Koagulum wird langsam wieder peptonisiert.

Mit Milzbrandvakzine geimpfte Tiere schieden nach Versuchen von N. ANToNI keine Milzbrandbazillen aus. Von solchen Tieren dürfte erst dann eine Gefahr drohen, wenn sie, wie es ab und zu bei besonderen Impfstoffen vorkommt, krank werden. Nach der Heilimpfung fieberlos gewordene Tiere sind nicht gefährlich, wenn nicht vor der Heilimpfung Euter oder Striche lokal erkrankt waren.

\section{Rauschbrand}

Rauschbrandbazillen wachsen in Milch schlecht, sie degenerieren. Die Krankheit hat keine Bedeutung für die Milchhygiene.

\section{Rotz (Malleus)}

GAFFKY erwähnt einen Fall, bei dem 2 Menschen auf Genuß von Milch einer an Rotz erkrankten Stute hin erkrankt sein sollen. Es ist nicht bekannt, 
ob andere Ansteckungsgelegenheiten fehlten. Marktmilch kommt als Überträgerin der Krankheit nicht in Betracht.

Keine wesentliche Bedeutung für die Milchhygiene besitzen die Rinder- seuche, eine durch bipolare Bakterien der Gruppe der hämorrhagischen Septikämie hervorgerufene, heute in Deutschland seltene Krankheit, die Rinderpest, die Lungenseuche, die ebenfalls nicht oder seit kurzem nicht mehr in Deutschland vorkommt, und die im übrigen nicht auf den Menschen übertragbar sind.

Die weitverbreiteten Erreger von Eiterungen oder Entzündungen anderer Art finden sich häufig in der Milch. Staphylokokken, Sarzinen und Streptokokken sind gewöhnliche Vertreter der Milchflora. Eine Bedeutung kommt diesen Bakterien, ebenso wie den Aktinomyzeten erst dann zu, wenn sie zufällig eine Euterentzündung verursachen. Milch aus solchen Eutern ist verdorben und ekelerregend.

Bevor auf die Bedeutung der übrigen Euterentzündungserreger eingegangen wird, seien noch die übrigen in unseren Milchviehbeständen zeitweise herrschenden Seuchen oder einzelne Tiere befallenden Tierkrankheiten, die auf den Menschen übergehen können, besprochen.

\section{Maul- und Klauenseuche}

Die Aphthenseuche oder Maul- und Klauenseuche ist eine hochakute, fieberhafte Erkrankung von außerordentlich leichter Übertragbarkeit. Mit dem strömenden Blut gelangt der Erreger vom primären Ansteckungsherd in der Zeit des Fieberanstieges in den ersten 24 Stunden oder ersten Tagen in alle Organe. In dieser Zeit kann der Erreger in der Milch ausgeschieden werden, auch ohne daß das Euter lokal erkrankt ist (ERnst und Göbel, LebaIlly und Porcher). Der Übertritt von Erregern ist besonders reichlich bei der bösartigen Form der Krankheit, oder wenn das Euter lokal erkrankt. Die Aphthen, die die ansteckende Lymphe enthalten, sitzen ja dann gewöhnlich im Strichkanal oder auf den Strichen. Seltener ist die Euterhaut befallen. Die Erreger sind unsichtbar, gehen durch Tonkerzen unter Druck in das bakterienfreie Filtrat über. Erkrankungen des Menschen nach Genuß von Milch, Rahm, Süßrahmbutter sind bekannt geworden durch die Arbeiten von Bussenius und Sieger, Jensen, Hertwig, Stickler, Schreyer, Krajewsky, Walkowsky, Gerlach und die Jahresberichte des kaiserlichen und des Reichsgesundheitsamtes.

Das Virus geht mit Sicherheit bei einer Erhitzung der Milch auf 60 bis $70^{\circ} \mathrm{C}$, bei Dauererhitzung bei 60 bis $63^{\circ} \mathrm{C}$ zugrunde. 3 bis 4 Tage alte, saure Milch ist nicht mehr ansteckungsfähig. Durch frischen Käse und durch Butter sind Übertragungen verursacht worden (Fröhner, Ebstein, THIELE, SCHNEIder, Frick, FröHLICH).

Besonders gefährlich sind Rahm, Sahne, Schlagobers und rohe Rahmspeisen aus Milch verseuchter Gehöfte.

\section{Maltafieber und seuchenhafter Abortus}

Unter „Maltafieber", Mittelmeerfieber ist eine Erkrankung der Menschen bekannt, die auf Malta bei Angehörigen der englischen Garnison zuerst bekannt und erforscht wurde. Die Krankheit entsteht durch Genuß von roher Ziegenmilch. Die befallenen Ziegen zeigen keine oder nur geringe Krankheitserscheinungen. Es ist ferner an den Küsten des Mittelmeeres, in Südafrika, in Indien, in China, auf den Philippinen, in Amerika beobachtet worden. In Deutschland ist die Krankheit noch nicht festgestellt worden. 
WEyraUch veröffentlicht einen Fall echten Maltafiebers bei einer Dame in Jena. Diese hatte an der Riviera ungekochte Ziegenmilch genossen. Das Blut agglutinierte das Bacterium melitense $1: 16000$. Kulturen aus dem Blut gelangen nicht mehr. BuRNET unterscheidet neben dem Bacterium melitense noch ein paramelitense (schlechte Agglutininbildner, agglutiniert häufig mit Normalserum). Der Erreger ist der Form und seinen Kultureigenschaften nach vom Bacillus abortus BANG nicht wegzukennen, aber der Epidemiologie nach sind die durch beide verursachten Krankheiten verschieden. Alle Allgemeinerkrankungen durch Bacillus abortus BANG, die mir bekanntgeworden sind und die den leichteren Fällen des Maltafiebers klinisch ähneln, betreffen Tierärzte, die sich bei ihrer Praxistätigkeit (Abnahme der Nachgeburten) ansteckten.

Die Nachrichten über Infektionen mit Bacillus abortus BANG durch Milchgenuß sind im Gegensatze zu der starken Verbreitung der Krankheit unter den Rindern sehr selten.

So meldet Favilli eine Erkrankung des Menschen, verursacht durch eine an Abortusinfektion erkrankte Kuh. Nach GRÄUBs Zusammenstellung sind in Italien, Frankreich und Amerika Krankheitsfälle bekanntgeworden, die auf Genuß abortusbazillenhaltiger Milch hin entstanden sind. Der Verlauf war dem Maltafieber ähnlich und trug typhösen Charakter.

Wenn man Affen mit Abortusbazillen per os infizieren will, so braucht man etwa 1000mal soviel Material als beim Maltafieber, mit dessen Erreger die Infektion sehr leicht gelingt (Fabian, Fleischner, Mayer und Shaw, Vecki).

Durch entsprechende Vorbehandlung mit Abortusbazillen kann man Affen gegen den Bacillus melitensis immunisieren. Deswegen ist es fast selbstverständlich, daß mit Abortus infizierte Kühe auch gegen Bacillus melitensis mit ihrem Blutserum reagieren. KEnNeDy hat 1914 bei einem hohen Prozentsatz von Kühen der Umgebung Londons Agglutinine gegen den Bacillus melitensis nachgewiesen. Auf die nahe Verwandtschaft beider Erreger haben A. Evans sowie ZELLER hingewiesen.

Die Impfreaktionen und die pathologischen Verhältnisse beim Meerschweinchen sind in beiden Fällen gleich. Mohler und Traum haben Material aus 56 Tonsillen und Drüsen von Menschen verimpft und erhielten einmal beim Versuchstier nach 3 Monaten die Erscheinungen der Abortusinfektion. Bei Verimpfung von Marktmilch kann man solche Veränderungen verhältnismäßig häufig $(4,6$ bis $36,8 \%)$ erzielen. Man untersucht die Impftiere dann nach 2 bis 6 Wochen öfters auf das Vorkommen von spezifischen Agglutininen im Blut, die frühestens 8, spätestens 28 Tage nach der Infektion auftreten. VERcellana glaubt durch Säureagglutination (1:100 Milchsäureverdünnung agglutiniert Maltakokken, nicht aber den Bacillus abortus BANG) die beiden Typen trennen zu können. Er gibt zu $1 \mathrm{~cm}^{3}$ Kulturabschwemmung $1 \mathrm{~cm}^{3}$ der Säureverdünnung.

In neuerer Zeit wurde von FicaI und AlessandrinI (zit. nach Favilli) angegeben, daß bei Erhitzung des Serums die Agglutination für Maltabakterien verschwinde, die für Abortus nicht. FaviLli kann dies nicht bestätigen, der Titer gegen beide nimmt gleichmäßig ab. Der Autor hält eine Infektion des Menschen auch durch Rohsalate für erwiesen. Der Nachweis durch Kultur gelingt nur, wenn die Milchproben unter sterilen Kautelen entnommen sind, auf Agar mit 1\% Traubenzucker und 5 bis 10\% sterilem Rinderserum. Auch Milchzuckerserumagar ist geeignet. Zur Unterdrückung Gram-positiver Bakterien kann man ferner 1:10000 Gentianaviolett zusetzen. Die Untersuchung der Marktmilch auf Abortusbazillen hat vorerst für die Milchkontrolle nur wissenschaftliches Interesse. 
202 W. ERNST: Pathogene Bakterien, die gelegentlich in der Milch vorkommen

\section{Rindertuberkulose}

Tuberkelbazillen können in die Milch gelangen aus tuberkulösen Menschen bei der Milchherstellung und Verleitgabe oder sie stammen aus tuberkulösen Tieren. Am 23. Juli 1901 erklärte R. KocH auf dem Londoner internationalen Tuberkulosekongreß, daß die Tuberkulose des Menschen und die des Rindes durch 2 voneinander verschiedene Tuberkelbazillen verursacht sei. Es ist heute allgemein anerkannt, daß zwischen dem Typus humanus und dem Typus bovinus konstante und tiefgreifende Unterschiede bestehen. Die Rindertuberkelbazillen sind besonders für das Rind, weniger für den Menschen gefährlich, umgekehrt ist der Tuberkelbazillus des Menschen für das Rind weniger virulent. Kossex, Weber und Heuss haben durch Impfrersuche am Rind erwiesen, daß Menschentuberkelbazillen in den regionären Lymphdrüsen zurückgehalten werden, während solche vom Rind zu fortschreitender Tuberkulose führten. Bei galaktiferer Infektion mit Typus bovinus entstand Eutertuberkulose mit fortschreitender Abmagerung und Tod als Folge, der Typus humanus erzeugte vorübergehende Entzündungsreizung und bindegewebige Atrophie des Euters (Nockard, Meyer, Calmette und Guerin sowie Zwick) ohne Beteiligung der Lymphdrüse. Kälber, die von solchen Eutern (Infektion mit Typus humanus) sich nährten, blieben meistens gesund, einmal entstand Darm- und Mesenterialtuberkulose.

Fast genau dieselben Verhältnisse sind beim Menschen-gegenüber dem Rindertuberkelbazillus zu finden. Der Mensch infiziert sich in der Hauptsache vom kranken Menschen her. Obwohl die Möglichkeit, mit Rohmilch Tuberkelbazillen aufzunehmen, sehr häufig gegeben ist, ist die Erkrankung der Menschen durch Typus bovinus sehr selten. Das für den Typus bovinus sehr empfängliche Schwein zeigt die Infektion unter Umständen außerordentlich häufig (Molkereischweine z. B.).

Tabelle I

\begin{tabular}{|c|c|c|c|c|}
\hline \multirow[b]{2}{*}{ Autor } & \multicolumn{2}{|c|}{ Art der Fälle } & \multirow{2}{*}{$\begin{array}{c}\text { Sitz der } \\
\text { Erkrankungen }\end{array}$} & \multirow{2}{*}{$\begin{array}{l}\text { Zahlen der Funde } \\
\text { von Typus bovinus }\end{array}$} \\
\hline & $\begin{array}{c}\text { Zahl } \\
\text { der Fälle }\end{array}$ & $\begin{array}{c}\text { Alter } \\
\text { der Kinder }\end{array}$ & & \\
\hline B. MöLLERS & $\begin{array}{l}2050 \\
- \\
- \\
- \\
-\end{array}$ & \begin{tabular}{|} 
unter 5 Jahren \\
5 bis 16 Jahren \\
über 16 Jahre \\
- \\
- \\
-
\end{tabular} & $\begin{array}{c}- \\
\text { - } \\
- \\
\text { Lungentub. } \\
\text { Fütterungstub. } \\
\text { andere Formen }\end{array}$ & $\begin{array}{c}1,86 \% \\
18,1 \% \\
15,8 \% \\
3,1 \% \\
0,5 \% \\
\text { Mehrheit } \\
16,8 \%\end{array}$ \\
\hline $\begin{array}{l}\text { LAWFORD } \\
\text { KNAGGS }\end{array}$ & -- & - & $\begin{array}{c}\text { Knochen, Gelenke } \\
\text { Zervikaldrüsen }\end{array}$ & $\begin{array}{c}\text { doppelt wie Typus } \\
\text { humanus } \\
65 \text { (abs. Zahl) }\end{array}$ \\
\hline $\begin{array}{l}\text { HART und } \\
\text { RABINOWITSCH }\end{array}$ & $\begin{array}{l}0,8 \text { bis } 2,59 \% \\
\text { d. Sektionen }\end{array}$ & 一 & $\begin{array}{c}\text { isoliert in den } \\
\text { Mesenterialdrüsen }\end{array}$ & $83,3 \%$ \\
\hline $\begin{array}{l}\text { GAFFKY, ROTHE, } \\
\text { UNGERMANN } \\
\end{array}$ & $\begin{array}{c}76 \text { von } 400 \\
\text { Kindern }\end{array}$ & Kinder & - & 1,32 bis $5,1 \%$ \\
\hline WEBER & - & Kinder & $\begin{array}{c}\text { Halsdrüsen } \\
\text { Mesenterialdrüsen }\end{array}$ & $\begin{array}{c}40 \% \\
40 \text { bis } 50 \%\end{array}$ \\
\hline
\end{tabular}

Bei dem für Menschen sehr günstigen Virulenzverhältnis des Typus bovinus müßten ungeheure Mengen von solchen Tuberkelbazillen genossen werden, um zum Haften der alimentären Infektion zu führen. Diese ist daher beim Menschen eine Seltenheit. Nur in etwa 8,6\% menschlicher Tuberkulose 
(1602 Fälle) fanden sich Tuberkelbazillen tierischer Herkunft, und zwar in etwa 8 davon solche des Typus bovinus. Bei der Lungenschwindsucht findet sich letzterer Typus nur in etwa $0,6 \%$, bei den übrigen Tuberkuloseformen in etwa $16 \%$. Bei Kindern ist das Verhältnis wesentlich schlechter: Hier sind unter 100 tödlichen Fällen fast 1/4 (24\%) durch den Typus bovinus erzeugt. Bei Gehirnhautentzündung sind dabei in etwa $11 \%$ Tuberkelbazillen tierischer Herkunft, 5\% bei Knochen- und Gelenktuberkulose (KossEL). Nimmt man zur Berechnung als Grundlage alle, nicht nur die tödlich verlaufenden Fälle, so fanden sich bei der Berliner Bevölkerung unter den infizierten Kindern nur 4 bis $5 \%$ zoogener Infektionen (KosSEL). Die Zahlen anderer Autoren sind ähnlich, aber naturgemäß verschieden, s. Tabelle S. 202.

Die Möglichkeit, mit Rindertuberkelbazillen sich $\mathrm{zu}$ infizieren, ist sehr oft gegeben. Die Zahlen der Fälle, in denen Tuberkelbazillen vom Rind in Marktmilch gefunden wurden, schwanken zwischen 10,5 und $61 \%$ der untersuchten Proben und je nach der Herkunft der Proben (Berlin, Halle, Leipzig, dänische Importmilch usw.), Milch einzelner Bestände, Mischmilch aus Molkereien usw. (Obermüller, Buege, Petri, Beck, Eber, KöHlisch). Bei Sammelmilch aus Molkereien ist der Prozentsatz hoch $(60 \%)$, während er bei Untersuchungen von 8070 Gesamtmilchproben aus einzelnen Herden, die dem Tuberkulosetilgungsverfahren angeschlossen waren, $7,23 \%$ betrug. In einzelnen Jahren schwankte der Prozentsatz zwischen 4,5 und $15 \%$ (Pröschold).

Tonney, White und Danforth fanden von 258 Proben Chikagoer Marktmilch $3,5 \%$ und einmal von 73 Proben $6,8 \%$ mit Tuberkelbazillen behaftet; das wären schätzungsweise täglich 43000 Quarts oder etwa 1640 Liter tuberkelbazillenhaltiger Milch für Chikago.

In einer Probe wurden Tuberkelbazillen von Typus humanus nachgewiesen (RABINOWITSCH).

In die Milch gelangen die Tuberkelbazillen vom Rind im wesentlichen aus offen tuberkulösen Tieren. Bei den Arbeiten der Tuberkulosetilgungsstationen der Landwirtschaftskammern fiel die Untersuchung von einwandfrei entnommenen Proben der Mischmilch stets negativ aus, wenn die Kühe mit offener Tuberkulose entfernt waren. MüLLER und Hessler fanden in 2949 Proben Mischmilch aus je 30 bis 200 Kühen 15lmal Tuberkelbazillen und in den betreffenden Herden 8 mal je 2 Kühe und 150mal je 1 Kuh mit Eutertuberkulose (113 Bestände), 16mal 1 oder mehr Kühe mit Tragsacktuberkulose, lmal Tuberkulose der Nieren oder Gebärmutter, 1mal Nieren- und Darmtuberkulose, Imal 1 Kuh mit Tuberkelbazillen im Sputum und 19mal offene Lungentuberkulose. Die übrigen Mischmilchproben enthielten keine Tuberkelbazillen, obwohl darunter noch zahlreiche Tiere standen, die tuberkulös infiziert auf Tuberkulin positiv reagiert hatten.

Wenn wir nach den Arbeiten von Delépin, Ravenel, Rabinowitsch und Kempner, Gehrmann, Gehrmann und Evans, Moussu, Mohlers auch annehmen müssen, daß Kühe, die ihre tuberkulöse Infektion lediglich durch Tuberkulinüberempfindlichkeit anzeigen, $\mathrm{ab}$ und $\mathrm{zu}$ Tuberkelbazillen in geringer Anzahl mit der Milch ausscheiden können, so müssen wir in Berücksichtigung der Erfahrungen der Tuberkulosetilgungsstationen doch ebenso annehmen, daß diese Ausscheidung in sehr geringer Quantität erfolgt, die Milch oft so wenig Tuberkelbazillen enthält, daß diese in der Mischung mit der Milch gesunder Kühe nicht mehr nachgewiesen werden können.

Die Milch von Tieren, die nur auf Tuberkulin reagieren, kann praktisch als völlig ungefährlich für den Menschen angesehen werden. Dagegen-muß die Milch von Kühen, die an äußerlich erkennbarer Tuberkulose, insbesondere des 
Euters, der Gebärmutter, der Lungen und des Darmes leiden, als geeignet, die menschliche Gesundheit zu zerstören, unter allen Umständen aus dem Verkehr ausgeschaltet werden.

Erfreulicherweise steigt bei den Tierbesitzern die Einsicht darüber, daß die Tuberkulosebekämpfung sehr große wirtschaftliche Vorteile bietet und daß ihre Einführung in den Beständen sich empfiehlt.

Die Tuberkulosetilgungsverfahren sind nach v. Ostentag imstande, die Tuberkulosebefallsziffern erheblich herabzudrücken. REGNER hat zusammengestellt, daß von 1366 Beständen anfangs mit insgesamt 49112 Tieren bei der ersten Tuberkulinisation 28,9\% reagierten. Im Jahre 1909 enthielten die Bestände insgesamt 57734 Tiere mit $3,1 \%$ reagierenden. In Dänemark konnte BANG die Zahlen von $40 \%$ im Jahre 1893 auf 8,5\% im Jahre 1908 herabdrücken, MALM in Norwegen 1896 bis 1903 von 8,4 auf 4,9\%, HoJER in Finnland von 24 auf $10,1 \%$ in den Jahren 1894 bis 1900 .

Nach Hutyra hatten in Mezöhegyes von 647 Rindern im Jahre 1898 26,6\% (von 329 Kühen 44,8\%) reagiert. 1903 reagierten von allen Tieren nur mehr $1,8 \%$, von 502 Kühen $2,8 \%$. In den 6 Jahren ist der Rinderbestand ohne Neuanschaffung um $75 \%$ gestiegen, der Prozentsatz der Reaktionen ist um $88 \%$ gefallen.

Das v. Ostertagsche Verfahren wirkt ebenfalls hervorragend. Es sanken die Zahlen der klinisch tuberkulösen Tiere in Ostpreußen in der Zeit von 1900 bis 1904 von 2,7 auf $1,3 \%$; in Pommern 1902 bis 1906 von 2,93 bis $0,6 \%$, in Brandenburg von 3,46 bis 1,5\% (1903 bis 1907), in Schleswig-Holstein 1903 bis 1906 von 2,8 bis $1,93 \%$, in Sachsen von 3,6 bis $2,41 \%$ (1903 bis 1907), in Westfalen von $4,7(1909 / 10)$ auf $2,3 \%(19011 / 12)$, in Pommern von 2,62 (1902/03) auf 1,01\% (1904/05), 0,6\% (1906/07), 0,35 (1908/09), 1,3\% (1912/13).

Das sind, nach den Prozentsummen gerechnet, Zahlen, die vielleicht an sich wenig auffallen, aber bedeutend werden, wenn man die Gefahrenminderung ins Auge faßt.

Die Tuberkulosebekämpfung ist ein Problem, das nur Erfolg haben kann, wenn man es als Wirtschaftsaufgabe einleitet. Sie wird scheitern, wenn gleich anfangs allzu einschneidende Forderungen gestellt werden. Es empfiehlt sich daher, zu Beginn der Tilgungsarbeit die Feststellung der Zahl der verseuchten Bestände und der darin enthaltenen klinisch verdächtigen, hochwahrscheinlich kranken und kranken Tiere in den Vordergrund der Tilgungsarbeit zu stellen und dabei die Tierhalter zu überzeugen, wie unwirtschaftlich die Haltung solcher Tiere ist. Letzteres ist nicht schwer, und die Überzeugung, daß rascheste Ausmerzung solcher Tiere im Belange der Wirtschaft liegt, die Folge.

Nun erst wird auf die Gefahr der Ansteckung hingewiesen und die Notwendigkeit tuberkulosefreier Aufzucht erläutert. Gerne lassen sich die Landwirte darauf ein, Laufkoppeln und Jungviehweiden zu errichten. Schwierig ist manchmal die frühzeitige Trennung der Kälber vom übrigen Bestand durchzusetzen. Häufig schwierig deswegen, weil eben die Raumfrage eine maßgebende Rolle spielt. Es genügt aber die Trennung in einem Raum, der mit Brettern in Nut und Federn verfugt, vom Boden bis zur Decke vom allgemeinen Stall abgegrenzt ist. Die Ernährung mit bazillenfreier Rohmilch (Ammenmilch) aus sorgfältig ausgewählten Kühen wird durchwegs der Ernährung mit erhitzter Milch vorgezogen. Bei Ernährung mit erhitzter Milch wird allgemein über die Entstehung von Durchfällen geklagt. Nach dem Absetzen werden die Kälber der Tuberkulinprobe unterzogen und die Zuchttiere nur von den nicht reagierenden ausgewählt. Der genauen klinischen Untersuchung auf offene Tuberkulose werden die Tiere mindestens $1 \mathrm{mal}$ im Jahre, besser 2 mal unterworfen. 
Die Mischmilch der Herden wird 2- bis 4 mal im Jahre auf Tuberkelbazillengehalt geprüft. Nach jedem Fund von Tuberkelbazillen wird sofort eine außerordentliche Untersuchung des Bestandes eingeschoben.

Hat man auf diese Weise die Tuberkulose nach einigen Jahren auf ein niederes Maß herabgedrückt, dann mag das BANGsche Verfahren Platz in solchen Beständen greifen, in denen die Raum- und Personalfrage es ermöglicht. Die Ausmusterung klinisch erkrankter Tiere geht wie bisher weiter. Die klinisch gesunden Tiere aber werden sämtlich tuberkulinisiert. Die reagierenden Tiere werden abgesondert. Die Trennung von den nicht reagierenden Tieren muß energisch durchgeführt werden. Die Pfleger der reagierenden Gruppe dürfen nicht in Berührung mit denen der nicht reagierenden kommen. Jede Gruppe hat auch ihren eigenen Bullen. Tiere der reagierenden Gruppe, die klinisch erkennbar erkranken, sind möglichst bald der Schlachtung zuzuführen. Jungtiere, die reagieren, werden von der Zucht ausgeschlossen oder sind wenigstens der reagierenden Gruppe zuzuteilen.

Tiere unter einem halben Jahr, die Reaktionen geben, sind der Schlachtung zuzuführen. Die Kälber der nicht reagierenden Kühe bleiben bei der Mutter, die der reagierenden Kühe bekommen am ersten Tag das Kolostrum der Mutter, um dann in die Gesundenabteilung zu kommen. Sie werden dort mit der Milch der gesunden Kühe aufgezogen oder Ammenkühen zugeführt. Nach dem Absetzen werden alle Kälber möglichst bald der Tuberkulinisation unterworfen und die reagierenden ( 1 bis $2 \%$ ) geschlachtet. Vor dem ersten Sprung werden die Kalbinnen wieder mit Tuberkulin geprüft und je nach dem Ausfall den einzelnen Gruppen zugeteilt. Die Tuberkulinisation wird alljährlich wiederholt. Bei Zukauf wird jedes Stück klinisch und durch Tuberkulin geprüft.

Schutzimpfungen gegen Tuberkulose ergeben nur eine vorübergehende Erhöhung der Widerstandskraft. EBER hat 1917 nach eingehendster Prüfung und Zusammenstellung der bis dahin bekanntgewordenen Ergebnisse diese dahin zusammengefaßt, daß es zur Zeit kein Schutzimpfungsverfahren gibt, ,,welches imstande wäre, Rindern einen ausreichenden Schutz gegen die natürliche Tuberkuloseansteckung zu verleihen. Auch die bei der Anwendung einzelner Impfstoffe gelegentlich zu beobachtende Heilwirkung auf bereits vorhandene tuberkulöse Prozesse ist kein Faktor, mit dem bei der Bekämpfung der Rindertuberkulose ernstlich gerechnet werden kann".

Von dem Friedmannschen Tuberkuloseschutz- und Heilmittel sowie von der Ponndorf-Impfung ist nach Versuchen von E. Meyer und von A. Immamura und J. NAKADA gleiches zu sagen. Demnach bleiben zur Tuberkolusebekämpfung nur die bisher bewährten sanitätspolizeilichen Maßnahmen und die Besserung der allgemeinen Verhältnisse der Aufzucht, Haltung und Pflege.

\section{Der Nachweis von Tuberkelbazillen in Milch}

Der Nachweis von Tuberkelbazillen kann durch Mikroskopie und durch den Impfversuch versucht werden. Der mikroskopische Nachweis arbeitet nicht schlecht bei Einzelkuhproben und besonders bei Viertelsproben verdächtiger Tiere.

Der lufttrocken gewordene Ausstrich des Sediments kann ohne weiteres nach Hitzefixation der Färbung unterworfen werden; Rahmaufstriche werden nach der Fixation entfettet oder in Ätheralkohol fixiert.

Die Färbung auf Tuberkelbazillen geschieht mit Karbolfuchsinlösung (1 Teil Fuchsin auf 10 Teile absoluten Alkohol und 90 Teile 5\% Karbolsäurewasser), unter Erwärmen. Das gefärbte Präparat wird dann rasch in $33 \%$ iger 
Schwefelsäure geschwenkt und mit Alkohol abgespült. Die Entfärbung wird durch Wasserspülung unterbrochen und das Präparat in seinen entfärbten Teilen mit wässerigem Methylenblau oder Methylgrün nachgefärbt.

Bei Marktmilch gibt diese einfache Methode gewöhnlich negative Resultate. Nicht nur, daß aus Kot- und Futterteilchen andere säurefeste Stäbchen Tuberkelbazillen vortäuschen können (manche davon sind der Größe und Form nach sehr ähnlich), es sind die Tuberkelbazillen auch meistens in so geringer Anzahl vorhanden, daß man sie im einfachen Ausstrich übersieht. Man wendet deshalb besondere Kunstgriffe an, z. B. die Homogenisation der Milch vor dem Ausschleudern. KNUT ARNell mischt $25 \mathrm{~cm}^{3}$ Milch in einem Scheidegefäß mit $2 \mathrm{~cm}^{3}$ Liquor ammonii caustici, gibt $100 \mathrm{~cm}^{3}$ Äther-Petroläther-Gemisch (zu gleichen Teilen) zu, schüttelt mehrmals, bis das Fett sich löst, läßt ruhig zur Abscheidung stehen und nimmt die unten befindliche, durch einen Hahn abgelassene wässerige Schicht. Diese wird 15Minuten lang zentrifugiert; der Bodensatz gefärbt.

ThöRner mischt $20 \mathrm{~cm}^{3}$ Milch mit $1 \mathrm{~cm}^{3} 50 \%$ Kalilauge - Einstellen in kochendes Wasserbad - Zentrifugieren - Untersuchung des Bodensatzes.

ILKEWITSCH und THöRNeR geben folgendes Verfahren an: Zu $20 \mathrm{~cm}^{3}$ Milch wird verdünnte Zitronensäure bis zur Gerinnung zugesetzt. Die durch Filtration gewonnenen Gerinnsel werden in Wasser mit etwas phosphorsaurem Natron gelöst, die Lösung 10 bis 15 Minuten in einem Scheidetrichter mit $6 \mathrm{~cm}^{3}$ Äther geschüttelt, die unten stehende Flüssigkeit abgelassen, zu ihr so viel Essigsäure zugesetzt, daß eben Trübung eintritt, und dann scharf zentrifugiert. Untersucht wird der Bodensatz.

Biedert nimmt $\mathrm{zu} 10 \mathrm{~cm}^{3}$ Milch $100 \mathrm{~cm}^{3}$ Wasser und 4 bis 8 Tropfen Natronlauge - Schütteln - Kochen - Stehenlassen - Untersuchen der Flocken am Boden.

Schmit und Pröschold setzen zu Milch das 9- bis 10fache einer 2,5\%igen Antiforminlösung, gelöst in frisch destilliertem Wasser oder solchem, das nachweislich keine säurefesten Stäbchen enthält, lassen $1 / 2$ bis 2 Stunden stehen und zentrifugieren.

Zwick, Schmitr und Pröschold haben ferner die bei der Butyrometrie angewandten Zusätze der Sal- oder Neusalmethode für Homogenisation gut befunden.

ANDERSEN behandelt den Zentrifugenbodensatz mit 10 bis 15\% Antiformin und gewinnt daraus erneut den Bodensatz. Er zieht diese Methode allen anderen vor.

Der sicherste Nachweis der Tuberkelbazillen ist der durch Impfung. Die Milchprobe wird zentrifugiert, der Bodensatz mit Rahm vermischt, mit geringen Mengen der Magermilch verrührt und dann am besten intramuskulär in der Menge von 0,5 bis $1 \mathrm{~cm}^{3}$ einem Meerschweinchen an einem hinteren Oberschenkel eingespritzt. Auch 1 bis $2 \mathrm{~cm}^{3}$ Vollmilch kann verwendet werden (v. OstertaG, Schmitt und Pröscholdt).

Nach einigen Wochen sind Lymphknotenschwellungen vorhanden. Die auf nicht tuberkulöser Basis entstandenen sind in der Zwischenzeit wieder verschwunden. Sind die regionären Lymphdrüsen hart geschwollen, so kann man die Tiere töten oder man wendet vorher noch die intrakutane Tuberkulinprobe an (Römer: 0,02 Tub. bovin. in 0,2 steriler Kochsalzlösung und davon $0,2 \mathrm{~cm}^{3}$ in die enthaarte Haut). Von den verendeten oder getöteten Tieren werden die grünlichweißen Nekrosestellen der geschwollenen Lymphknoten - geeignet sind am meisten die Kniefaltenknoten, Darmbeinknoten - zu Aufstrichen verrieben, fixiert und gefärbt. 
Zum Versuch soll man der Sicherheit wegen stets 2 Meerschweinchen verwenden ( $v$. Ostertag).

Wieweit zum Nachweis der Tuberkelbazillen in Milch sich Kulturverfahren eignen, ist noch nicht nachgeprüft, doch könnte das Verfahren, das. J. НонN angibt, sich dazu eignen, wenn man Rahm und Bodensatz verwendet: Zum Abtöten der Begleitbakterien hat sich 10 bis $12 \%$ Schwefelsäure bewährt, die 20 Minuten einwirken soll. Nach Schütteln in Röhrchen wird zentrifugiert und das Sediment, wie es ist, auf 3 Eiernährböden gebracht. Diese bestehen nach LubEnau aus 3 Teilen ganz frischen Eies (Dotter und Eiweiß) und 1 Teil $5 \%$ Glyzerinbouillon. Diese wird natursauer verwendet und besteht wieder aus je $1 \%$ Liebigs Fleischextrakt und Pepton und 0,5\% Kochsalz mit 5\% Glyzerin, vorsichtig erstarren lassen! Zusatz von $0,5 \mathrm{~cm}^{3}$ obiger Bouillon als künstliches Kondenswasser, Verschluß mit zeresingetränkten Zellstoffstopfen. Das Wachstum geht nach 8 bis 27 Tagen an. Die Methode ginge verhältnismäßig rasch. Sie war mit Material vom Menschen sehr sicher und dem Tierversuch überlegen.

SEELEMANN und KLINGMülLER haben das Säureverfahren mit 10 bis $15 \%$ zur Herausholung des Tuberkelbazillus aus verschiedenem Ausgangsmaterial mit Erfolg durchgeführt. Sie wandten das oben beschriebene Verfahren an, doch konnten sie nicht erweisen, daß die Methode den Tierversuch ersetzen könnte. Die Meerschweinimpfung war der Züchtung an Sicherheit überlegen.

Bei der Auswertung von Tuberkelbazillenfunden dürfte größte Vorsicht am meisten Erfolg zeitigen. Es wird sich empfehlen, lediglich durch sofortige tierärztliche Untersuchung des Bestandes die Tuberkuloseausscheider ermitteln und von der Milchproduktion ausmerzen zu lassen und die sonstigen Maßnahmen der Tuberkulosebekämpfung einzuleiten. Falls durch die Verimpfung von Milch oder durch Kulturverfahren die Bakterien nachgewiesen sind, das ist 2 bis 6 Wochen nach Inverkehrgabe der Milch, ist zu bedenken, daß z. B. durch Verkauf, Schlachtung die Bazillenausscheiderin längst entfernt, die einschlägige Milch längst wieder frei von Tuberkelbazillen sein kann.

Unter Umständen würden gerade die Tierbesitzer, die durch ihren Beitritt zum Tuberkulosetilgungsverfahren und die Unterstellung ihrer Produktion unter periodische tierärztliche Kontrolle zeigen, daß sie Bestes leisten wollen, den stärksten Schaden erleiden, während die Gleichgültigen und Fahrlässigen solchen Schäden weniger ausgesetzt sind.

Milch einzelner klinisch erkennbar tuberkulöser Kühe, besonders eutertuberkulöser, gehört außer Verkehr.

\section{Mastitiserreger}

Treten Euterentzündungen auf, so können deren Erreger naturgemäß in die Milch kommen. Dies wird in besonderem Maße dann der Fall sein, wenn die Entzündungen des Euters langsam, unkennbar einsetzen, weniger dann, wenn hochakute Entzündungen rasch zum Milchversiegen führen. Zu den in den meisten Fällen chronisch verlaufenden Entzündungen gehören die Eutertuberkulose, die im vorstehenden Absatz bereits besprochen ist, dann die Streptokokkenmastitis, ferner die Pyobazillose. Wenig Bedeutung für die Milchhygiene haben die sehr seltenen Fälle der Euteraktinomykose.

Akute Erscheinungen rufen die bei Tieren vorkommenden Vertreter der Koli-Typhus-Gruppe hervor, die Kolibazillen, der Bacillus Breslaviensis und Bacillus GÄRTNERI.

Das Prozentverhältnis des Vorkommens einzelner Gruppen ist nach Haltung und Pflege verschieden. Die Infektion mit Bacillus pyogenes z. B., 
ist meistens als Weideseuche bekannt; die Streptokokkenmastitis ist bei vorwiegender Stallhaltung in den Abmelkwirtschaften verbreiteter als sonst. VRIJBURG fand in 68,4\% Streptokokken, in $14.5 \%$ Bacillus pyogenes, in $7 \%$ Staphylokokken, in $5 \%$ Bacterium coli und in 2,4\% der Euterentzündungen Tuberkelbazillen.

Die meisten dieser Erreger finden ihren Weg durch den Zitzenkanal ins Euter, nur der Tuberkelbazillus gelangt vom Blute her metastatisch in die Drüse. Eine Infektion von der Zitze her ist besonders bei feuchter Streu und unter Beteiligung von Fliegen (Bacillus pyogenes auf der Weide) sehr leicht denkbar. Manche Autoren halten die Besiedlung der Zisterne mit Bakterien noch nicht für einen anormalen Zustand (STECK). Der Reiz kann geringfügig bleiben und es bildet sich ein Gleichgewichtszustand heraus zwischen Keimwachstum und wachstumhemmenden Faktoren. Erst wenn dieser Gleichgewichtszustand gestört wird, z. B. durch Milchstauung (STECK), Verwundung der Schleimhaut, Quetschung (GöTZE), dann wird aus dem normalen Zustand ein pathologischer, und das Sekret wird verändert. STECK hat besonders Streptokokken als Besiedlungsbakterien gefunden. C. GORINI unterscheidet neben der Zitzenmikroflora die „Euterkokken“, den Mammokokkus (Coccus mammarius), die Säure oder Säure und Lab bilden und sich bei $3 / 4$ aller Kühe bis in das Drüsenparenchym hinauf finden sollen.

Unter solchen Umständen wird auch die Infektion des Parenchyms leicht verständlich. Das ,Gleichgewicht“ wird leicht gestört, und die Drüse reagiert darauf durch Funktionsstörungen und leichtere oder energischere Abwehrmaßnahmen. Von der chemischen Zusammensetzung eines normalen zum leicht veränderten Eutersekret (räßsalzige Milch) bis zum hochgradig veränderten Produkt bestehen ununterbrochen fließende Übergänge (KöSTLER, STECK, RADOSAVLJEVITCH).

Der Nachweis solcher Besiedlungen des Euterkanalsystems kann auf zweierlei Weise versucht werden: 1. durch die Mikroskopie des Rahmes und Bodensatzes, und 2. durch sterile Entnahme von Proben und deren Bebrütung, oder besser, um die elektive Wirkung der Milch auszuschalten, durch Verarbeitung zu Agarund Gelatineplatten.

Bei chronischen Euterentzündungen empfehlen sich folgende Methoden:

Zentrifugieren der Proben in TrommsdoRFF-Röhrchen, Ausgießen der Milch, Aushebern des Bodensatzes mit einer feinen Platindrahtschleife, Ausstreichen auf dem Objektträger, Färben mit dünner, wässeriger Thioninlösung, Untersuchen auf Diplokokken, Streptokokken usw. (siehe I. Band, I. Teil, S. 365 u. 366, I. Band, 2. Teil, S. 289). Man wird so häufig Gelegenheit haben, Vertreter der Streptokokken und andere Keime zu finden. Die Methodik ist für Scheidung gesunder und mit Streptokokken infizierter Kühe (verdächtiger und kranker) außerordentlich wertvoll. Sie gibt rasch und mit großer Sicherheit einen Überblick. Alle Tiere, die wesentliche Mengen von Diplokokken oder Streptokokken und nennenswerte Mengen Leukozyten ausscheiden, sind der Infektion oder der Streptokokkenmastitis verdächtig, alle, bei denen größere Mengen von Leukozyten mit Diplokokken, mit Streptococcus brevis oder Streptococcus longus gefunden werden, sind je nach dem Befund als hochwahrscheinlich krank oder als krank an infektiösem Galt zu bezeichnen.

Für Marktmilch ist die Mikroskopie die einzige Methode, um aus dem Funde der sogenannten ,tierischen Streptokokkenformen“ auf das Beimelken von galtkranken Tieren zu schließen.

Zur weiteren Unterscheidung der Streptokokken müssen besondere Untersuchungsmethoden herangezogen werden. Unter diesen scheint zur Ein- 
gruppierung besonders geeignet die Züchtung auf Blutagar (SCHOTTMüLLER). Die Galtstämme verhalten sich dabei wie die weniger pathogenen Stämme des Menschen (GMInder, eigene Erfahrung). Ferner empfiehlt sich die Züchtung in Milch. Auch hier verhalten sich die Galtstämme ähnlich wie der Streptococcus pyogenes und Streptococcus mitis (Sv. WALL). L. HeIm trennt den Säurestreptokokkus (Streptococcus lactis KRUSE, Streptococcus lacticus LISTER), durch das Wachstum in $7 \%$ Lackmusmilch von anderen Stämmen ab. Dabei traten in dem Substrat folgende Veränderungen auf:

1. a) Die Milch wird weiß und gerinnt binnen 7 bis 17 Stunden (Streptococcus lactis, Stämme aus Bindehautentzündung, aus einem Hautpustelchen, aus Lumbalsekret, aus Stuhl und Harn). b) Die Milch wird weiß bis auf eine bläuliche Schicht, die sich später nach unten verbreitert, mit Weißlich wechselt oder ins Rötliche übergeht. Es besteht keine oder verspätete Gerinnung (Stämme des Streptococcus lactis mit vermindertem oder fehlendem Säurebildungsvermögen, Stämme aus Pockenlymphe, aus Stuhl).

2. Die Lackmusmilch wird erst rot, dann teilweise weiß. a) Sie wird erst rosa oder deutlicher rot, später unten teilweise weiß, schließlich im ganzen rot und gerinnt vollständig oder nur teilweise (Stämme aus Rotlauf, Phlegmone, Pyogenesstämme aus Marktmilch, Stämme aus kranken Zähnen). b) Die Milch wird erst ein wenig rosa, dann mitunter in der Kuppe weiß, später dauernd bläulichrot und bleibt flüssig, höchstens daß in der Kuppe etwas Gerinnsel auftritt (Pyogenesstämme aus Eiter).

3. Die Lackmusmilch wird nie weiß: a) Bald stärker, bald schwächer rot und gerinnt (ein Stamm starrer Streptokokken aus Milch). b) Ebenso, aber die Gerinnung setzt verspätet ein, wird nicht vollständig oder bleibt aus (Streptococcus pneumoniae, Streptococcus aus Pulpitis und anderen Zahnkrankheiten). c) Die Milch bleibt blau, wird höchstens schwächer blau oder schwach rötlich mit Blaustich, sie gerinnt nicht (Stämme aus Rotlauf, Phlegmonen, Streptococcus longissimus aus Zungenbelag und Stämme aus Zahnkrankheiten).

Die Hermschen Versuche bauen auf der Feststellung Estens auf, der 1909 erwies, daß Streptococcus lacticus KRUSE Lackmusmilch entfärbt, und der Hastings, der 1911 feststellte, daß sich die Milchsäurestreptokokken von anderen Streptokokkentypen der Milch dadurch unterscheiden, daß sie die Milch erst nach der Entfärbung zur Gerinnung bringen. SHERMaN und Albus zeigen 1918 den Weg, den Streptococcus pyogenes durch Lackmusmilch von dem Streptococcus lacticus zu trennen. RudoLf hat das Verfahren 1926 dazu benützt, den Typus des Streptococcus mastitidis von den Milchsäurestreptokokken wegzubekommen, letztere sollen innerhalb 24 Stunden die Milch zur Gerinnung bringen.

Nach KLIMMER und HAUPT bringen sie Lackmusmilch bei $10^{\circ}$ und bei $37^{0}$ zur Gerinnung und reduzieren gleichzeitig. Nach der Entfärbung wird die Milch von oben her fortschreitend nach unten rot. Auch der Mastitisstreptokokkus bringt die Milch zur Gerinnung und in der unteren Hälfte zur Entfärbung, aber schwächer und nur bei $37^{\circ}$. Bei $10^{\circ}$ tritt weder Säuerung noch Reduktion ein.

Galtstreptokokken bilden in Milchzuckerbouillon Flocken ohne Trübung, Milchsäurestreptokokken trüben zuerst die Bouillon und flocken sie dann unter Aufhellung aus. Auch auf Blutagar nach BROwN zeigen sich Unterschiede und insbesondere auch bei der Reduktion von Janusgrün und Molybdat, die beide von Galtkokken nicht reduziert werden.

Eine Arbeit neuerer Zeit von Demeter befaßt sich mit den besonderen Wachstumsbedingungen (Sauerstoff, Temperaturen, Zugabe von Stimulantien oder Nährstoffen), die den Reaktionsablauf und das Bild der Reaktion beein- 
flussen. Demnach unterscheiden sich die Milchsäurestreptokokken von den anderen Typen.

Die Beobachtung der Einsaaten hat mehrere Tage nacheinander zu geschehen. Die Kultureigenschaften der Streptokokken sind bekanntlich leicht veränderlich; eine stark säurebildende Art kann durch langes Weiterzüchten in Milch die Eigenschaften verlieren und $\mathrm{zu}$ einer schleimbildenden Art werden. Streptokokken finden sich in jeder Milch, Galtstreptokokken in nur 20 bis $40 \%$ der Marktmilchen. Trotz dieser großen Häufigkeit sind Erkrankungen des Menschen, die auf Genuß solcher Milch entstanden sein sollen, sehr selten. Die 2 Fälle mit schweren Erkrankungen von HoLST - (1894) Darmkatarrh — oder von JoHANNESEN (4 Kinder) - Darmkatarrh - , von JAKoBSEN - Diarrhoe, Erbrechen, Fieber -, von Edwards und Severn - Tonsillitis -, von LAMERIS und v. HarReveld Massendiarrhoe auf Genuß gekochter Milch - ließen bei Nachforschung zwar Kühe mit Streptokokkenmastitis bei den betreffenden Milchlieferanten nachweisen, das ist aber bei der Häufigkeit der Streptokokkenmastitis in einzelnen Beständen und bei der verhältnismäßig großen Ausbreitung unter den Beständen kein Wunder. Der Nachweis, daß die Krankheiten, die angeführt sind, tatsächlich durch Galtstreptokokken verursacht sind, ist nicht erbracht. In einem neueren Fall in New York (v. OstertaG) wurde zwar auch in der verdächtigen Milch Sekret galtkranker Euter, daneben aber nach genauester Untersuchung Paratyphusbazillen ermittelt. Trotzdem darf das Sekret aus kranken Vierteln mit Streptokokkenmastitis nicht der Mischmilch zugemolken werden. Milch, die nachweislich mit Galtsekret verunreinigt ist, ist verdorben im S. d. R.-N.-M.Gs., und unter Umständen ekelerregend. Nebenbei gesagt, ist die Galtmilch in der Hartkäserei besonders gefürchtet.

Ähnlich ist Milch aus Vierteln zu beurteilen, die mit dem Bacillus pyogenes infiziert sind. Er läßt sich schlecht nachweisen durch gewöhnliche Färbung, schlecht durch GRAMsche Färbung, bei der WEIGERTschen Färbung ist er positiv. Positive Anhaltspunkte zur Beurteilung der Frage, ob Milch mit Sekret aus pyogeneskranken Eutern gesundheitsschädlich ist, liegen nicht vor.

\section{Die akuten Mastitisformen}

Tiere, die an akuter Euterentzündung leiden, dürfen nicht oder nicht vor bakteriologischer Entscheidung der Infektionsart zur Herstellung von Genußmilch, Trinkmilch dienen. Auch die Milch gesunder Striche neben den akut erkrankten Vierteln ist verdächtig, mit den in Frage kommenden Erregern verunreinigt zu sein, und daher vom Nahrungsmittelverkehr auszuschalten. Neben den im Darm unschädlichen Koli- und Aerogenes-Bazillen finden sich unter den Erregern der akuten, unter Fieber mit Allgemeinerscheinungen und hochgradiger Schwellung des infizierten Viertels einsetzenden Euterentzündungen Vertreter, die beim Menschen vom Darm her schwere Intoxikationen hervorrufen. Es besteht kein Zweifel, daß die bisher nach Milchvergiftungen aufgetretenen Krankheitserscheinungen, wie Fieber, Mattigkeit, Ohnmachten, Ưbelbefinden, Erbrechen, Durchfälle, Wadenkrämpfe (JAKoBSEN) oder Schüttelfrost, Übelkeit, Kopfschmerzen, später Durchfall, Erbrechen, Durstgefühl durch Enteritisbakterien hervorgerufen sein können. Die Milch liefert diesen „Parathyphusbazillen“ günstige Vermehrungsmöglichkeit. WEICHEL berichtet über einen Fall, in dem sogar das Sekret aus einer „Kolimastitis“ bei Frau und Tochter des Tierbesitzers Durchfälle hervorgerufen hat. WEIGmanN und TH. GRUBer referieren über einen Fall von Gesundheitsschädigung durch Dickmilch, die aus Mastitismilch hergestellt war. Sie führen die Erkrankung auf ein Bacterium coli immobile (Ruhrbazillus ?) zurück. 
WEICHEL hat aus septischer Mastitis einen „Paratyphusstamm“ isoliert, damit auch das Euter einer Ziege infiziert und nach Auftreten von Euterentzündung beim Versuchstier mit dessen Sekret einen Hund gefüttert, der bereits 3 Stunden darnach schwere Intoxikationserscheinungen aufwies. Einem zweiten Versuchshund ging es ebenso.

Kochen genügt nicht, um die Toxine der in Frage kommenden Bakterienstämme $\mathrm{zu}$ zerstören.

Die Untersuchung auf Bakterien der ganzen Gruppe geschieht bei stark veränderten Sekreten einzelner erkrankter Viertel durch Anzüchten auf Anreicherungsnährböden. Für diese Gruppe eignen sich Nährböden mit Zusätzen von Kristallviolett oder Malachitgrün, z. B. Lackmus-Laktose-Agar nach v. Drigalski-ConRadi: $1000 \mathrm{~cm}^{3}$ Fleischwasser $+10 \mathrm{~g}$ Nutrose $+20 \mathrm{~g}$ Agar wird 1 Stunde gekocht, filtriert und auf $\mathrm{p}_{\mathrm{H}}=7,6$ eingestellt, dann heiß dazugemischt eine 25 Minuten lang gekochte Lackmuslösung, der nach 10 Minuten Kochen $15 \mathrm{~g}$ Milchzucker zugesetzt worden war. Ist der Schüttelschaum der Mischung nicht blau, wird noch Sodalösung zugegeben. Dazu kommen noch $10 \mathrm{~cm}^{3}$ einer frisch hergestellten Lösung von 0,1 Kristallviolett-B in $100 \mathrm{~cm}^{3}$ erwärmter Aqua destillata, dann folgt die übrige Sterilisation. Sehr zu empfehlen ist ferner der Chinablau-Malachitgrün-Agar nach BITTER: 1000 Nähragar, 20 Milchzucker, 10 Minuten kochen, dazu 90 Tropfen gesättigter Chinablaulösung (HöcHST) in Wasser und $25 \mathrm{~cm}^{3} 0,1 \%$ Malachitgrün (krist. extra Höchst) abfüllen, entkeimen!

Die Kolibazillen wachsen auf dem ersten Nährboden rötlich, die „Fleischvergifter" und Paratyphus B blaugraudurchscheinend, ähnlich Typhus. Auf dem zweiten Nährboden werden die Paratyphus- und Enteritidiskeime stark hervortreten.

Andere geeignete Anreicherungsverfahren sind sterile Rindergalle oder Galle-Fleischbrühe-Mischungen $(20 \%$ Galle $)$ oder Galle-Malachitgrün nach HODER.

Zur Bakterienauslese nimmt man ferner Endos Fuchsin-Laktose-Agar, auf dem Kolibazillen tiefrot bis metallisch glänzend wachsen, die übrigen blaß, oder Bromthymolblau und andere. Die verdächtigen Keime dürfen die GRAMsche Färbung nicht behalten und müssen beweglich sein. Dann werden sie in der ,bunten Reihe“ und durch serologische Methoden eingestuft.

STANDFUSS hat eine klare Zusammenstellung über die biochemische Leistungsfähigkeit gebracht. Nach ihm wirken Kolibazillen kräftig auf Milch, Rohrzucker, Milchzucker, Glyzerin, Arabinose, Mannit, Traubenzucker; Lackmusmolke wird kräftig und dauernd rot. Der Bacillus enteritidis BresLaU wirkt kräftig auf Glyzerin, Dulzit, Arabinose, Mannit, Traubenzucker; Lackmusmolke wird schnell rot und schlägt in Blau um. Paratyphus B arbeitet ebenso, nur vergärt er Glyzerin langsam und Dulzit schwach und verzögert. Ebenso ähnlich ist es beim Bacillus enteritidis GäRTNER, der mit Glyzerin zeitlich wechselnde Reaktionen gibt, Dulzit kräftig angreift, aber die Arabinose nur verzögert und schwach. Paratyphus A greift kräftig an Dulzit, Arabinose, Mannit und Traubenzucker und gibt schnelle Rötung in Lackmusmolke, deren Umschlag in Blau ausbleiben kann. Der Typhusbazillus greift nur Traubenzucker an, Mannit nicht immer, die Lackmusmolke zeigt langsam fortschreitende Rötung.

Gerade die Mastitiserreger dieser Gruppe sind in ihrer genaueren Zugehörigkeit noch nicht bestimmt. 
Wir wissen noch nicht, welche genauere Verwandtschaft die bei Mastitis oder in Milch und Käse gefundenen „Paratyphuskeime“ zu den einzelnen Vertretern der Gruppe haben.

Finden sich in Marktmilch Keime der Gärtner- oder Breslad-Gruppe, so können sie von Tieren stammen, die im Anfang einer akuten Mastitis stehen oder davon geheilt erscheinen. Die Dauer der Ausscheidung der Bakterien beträgt nach FaUss 12 bis 30 Tage, bei tödlich verlaufenden Fällen der Tiere bis zum Tode. Sie nimmt ab oder hört auf, wenn die Milch sich wieder normal zeigt.

Die Gefahr, daß bei Gelegenheit von Eutererkrankungen Paratyphuskeime und Enteritisbazillen in die Milch gelangen, ist nicht groß. Das Euter reagiert gegen die einschlägigen Infektionen mit so stürmischen Erscheinungen, und die Milch versiegt so rasch unter dem Einfluß der nicht selten sehr schweren Allgemeinerkrankung, daß kaum zu befürchten ist, daß solche Sekrete in die Marktmilch eingemolken werden. Immerhin sind Paratyphuskeime in Milch gefunden worden, und zwar unter anderen von UHLENDORF und HüBENER, in 2 Fällen bei 100 Proben, von HüBener $4 \mathrm{mal}$ in 40 Proben und $3 \mathrm{mal}$ bei 30 und von KLEINe 9mal Enteritisbazillen in 39 Mischmilchproben. Sie können auch durch Verunreinigungen beim Melken oder durch infiziertes Kannenspülwasser in die Milch gelangt sein.

Im übrigen darf Milch nur dann bei einschlägigen „Milchvergiftungen“ bestimmt als Ursache angesehen werden, wenn kulturell, biologisch-chemisch und serologisch der Beweis erbracht ist, daß die Keime in der verdächtigen Milch und die im Stuhle der erkrankten Menschen gefundenen gleich sind, und daß sie in der Milch in einer Menge vorhanden sind, daß die Annahme einer Milchvergiftung gerechtfertigt erscheint.

Auch gelegentlich sonst, z. B. durch Verschmutzung mit Melkschmutz,könnten Keime der Enteritis-Gärtner- oder BreslaU-Gruppe in die Milch gelangen. Bekanntlich kommt Bacillus enteritidis GäRTNER bei Milchtieren als Krankheitserreger vor, nach LüTJE meistens in Einzelfällen, selten seuchenhaft. Besonders verdächtig sind Darmentzündungen, Erkrankungen der Geburtswege, der Luftwege, Gelenksentzündungen und fieberhafte Euterentzündungen oder fieberhafte Erkrankungen unbestimmten Charakters.

\section{Literatur}

Antoni, N.: Über den Einfluß der Pasteurschen Milzbrandschutzimpfung auf Fleisch und Milch geimpfter Tiere. Inaug.-Diss. Hannover. 1909. - ARNell: Über den Nachweis der Tuberkelbazillen in der Milch. Königl. Landbrucks akad. Scand. orle Tidskrift. 1894. - Ascher: Die Verbreitung von Typhus durch Milch usw. Vierteljahrsschr. f. gerichtl. Med., 9. Folge, Bd. 24, s. 132. 1902.

BANG: Die Tuberkulose unter den Haustieren in Dänemark. Dtsch. Zeitschr. f. Tiermed., Bd. 16, S. 401. 1890. - Über die Eutertuberkulose der Milchtiere und über tuberkulöse Milch. Dtsch. Zeitschr. f. Tiermed., Bd. 2, S. 62. 1885. — Experimentelle Untersuchung über tuberkulöse Milch. Ebenda, Bd. 17, S. 1. 1891. Über die Abtötung der Tuberkelbazillen bei Wärme. Zeitschr. f. Tiermed., neue Folge, Bd. 6, S. 81. 1902. - Barthel und Stenström: Beitrag zur Frage des Einflusses hoher Temperaturen auf Tuberkelbazillen in Milch. Zentralbl. f. Bakt., Abt. 1, Orig., Bd. 30, S. 429. 1901, ebenso Bd. 37, S. 459. 1904. - BASSENGE: Über das Verhalten des Typhusbazillus in der Milch und deren Produkten. Dtsch. med. Wochenschr., Nr. 9 u. 29. 1908. - BEck: Experimentelle Beiträge zur Untersuchung über die Marktmilch. Dtsch. Vierteljahrsschr. f. öffentl. Gesundheitspfl., Bd. 32, S. 430. 1900. - Zur Frage der säurefesten Bazillen. Tuberkul. 
Arb. a. d. K. Gesundheitsamte, S. 145. 1903. - Diphtherie. Handbuch der path. Mikroorganismen, Bd. 2, S. 754. Jena: G. Fischer. 1902-1904. - BitTeR, WEIGMANN und HABS: Bestimmung der gebildeten Säuremenge zur Unterscheidung verwandter Bakterien. Münch. med. Wochenschr., Nr. 23, S. 940. 1926. Bollinger: Milzbrand. Spez. Pathol. u. Therap. Bd. 3, S. 490. - Die Wutkrankheit des Menschen. Ebenda, S. 591. - Über Fleischvergiftung, intestinale Sepsis und Abdominaltyphus. Ärztl. Intellig.-Bl. 1880. - BoLLY und M. FIELD: Bacillus typhi abdominalis in milk and butter. Zentralbl. f. Bakt., Abt. 2, Bd. 4. 1898. - BRörs: Typhusbazillen in boter en karnemelk. Nederlantsch. Tijdschr. v. Geneesk., 40. Jahrg., II. Teil, S. 1260. 1904. - BRörS und TeN SANDE: Tuberkel- en Typhusbac. in Kefir. Nederlantsch Tijdschr. v. Geneesk. 42. Jahrg., Nr. 25. 1906. - BRUCK: Experimentelle Beiträge zur Frage der Typhusverbreitung durch Butter. Dtsch. med. Wochenschr., S. 460. 1903. BUEGE: Über die Untersuchung der Milch auf Tuberkelbazillen. (Inaug.-Diss. Halle a. d. S. 1896. Ref. Zentralbl. f. Bakt., I. Abt., Bd. 21, S. 70. 1897. Bussenius und SiEgel: Der gemeinsame Krankheitserreger der Mundseuche des Menschen und der Maul- und Klauenseuche der Tiere. Dtsch. med. Wochenschr., S. 65. 1897. - Kann Maul- und Klauenseuche auf den Menschen übertragen werden? Zeitschr. f. klin. Med., Bd. 32, S. 147. 1897.

CANTLEY : Report on the behaviour of the typhoid bacillus in milk. 26. Ann. rep. of the local government board. Suppl. Rep. of the medical officer, p. 243. 1896/97. CARo: Della maniera in cui i bacilli del carbonchio si comportano nel latte nelle prime 24 ore. La Rif. med., p. 84, 1893. Zentralbl. für Bakt. u. Parasitenkunde, 14. 1893. - Chamberland et Mousons: Experiences sur le passage des bactéridies charbonneuses dans le lait des animaux atteind du charbon. Compt. rend., T. 97, S. 1142. 1883. - CoNRADI: Eiskonservierung und Fleischvergiftung. Münch. med. Wochenschr., Nr. 18. 1909. - Eine neue Methode der bakt. Fleischbeschau. Zeitschr. f. Fleisch- und Milchhyg., 10. H. 1909. - Conradi, v. Drigalski und Jürgens: Über eine unter dem Bilde des Typhus verlaufende, durch einen besonderen Erreger bedingte Epidemie. Zeitschr. f. Hyg. u. Infektionskrankh., Bd. 42. - Cunningham: Die Milch als Nährmedium für Cholerakommabazillen. Scientific memoirs by medical officers of the army of India. Part V. Übers. v. Emmerich. Arch. f. Hyg., Bd. 12, S. 133.1891.

Demeter: Studien über Milchsäurestreptokokken. Bd. 5, Milchwirtschaftl. Forsch., Bd. 5, S. 505 bis 531. 1928. - v. Drigalski und Conradi: Über ein Verfahren zum Nachweis von Typhusbazillen. Zeitschr. f. Hyg. u. Infektionskrankh., Bd. 39. 1902.

EASTES: The pathologie of milk. Brit. med. Journ., Vol. 2, p. 1341. 1899. — EBER: Untersuchungen über den Tuberkelbazillengehalt der in Leipzig zum Verkauf kommenden Milch- und Molkereiprodukte. Zeitschr. f. Fleisch- u. Milchhyg. 1908. Feststellung einheitlicher Grundsätze für die Beurteilung der Tuberkulinreaktion beim Rind. Bericht über den VIII. Internat. tierärztl. Kongreß in Budapest. Ebstein: Einige Mitteilungen über die durch das Maul- und Klauenseuchegift beim Menschen veranlaßten Krankheitserscheinungen. Dtsch. med. Wochenschr., S. 37. 1896. - Ellenhorst: Die Milch als Verbreitungsmittel menschlicher Infektionskrankheiten. Inaug. Diss. Freiburg i. Breisgau. 1896. - EnDo: Über ein Verfahren zum Nachweis der Typhusbazillen (aus dem Privatinstitut v. Professor Dr. S. Kitasato). Zeitschr. f. Bakteriol., Abt. 1., Orig., Bd. 35, S. 109. 1903. Escherich: Ätiol. u. Pathog. d. epid. Diphth. Jahrb. f. Kinderheilk., 1899, Bd. 49, S. 163. Wien. 1894. - Über die Verbreitung des Scharlachs durch Milch usw. Münch. med. Wochenschr., S. 537. 1889. - EsSER und SchüTz: Mitt. aus amtl. Veterinärberichten. - Esten und Hastings, Ayers, Johnson und Mudge: Zit. n. Klimmer und HaUpt, siehe diese. - Evans: B. abortus in market milk. Science n. ser., 1915, Bd. 42, S. 352. 1916, ref. Zentralbl. f. Bakt., Bd. 63, Ref. S. 526. 1915. - EYRE: Contagious abortion and undulant fever. Brit. med. Journ, T. S. 554. 1925. - The bac. diphtherial. in milk. Brit. med. Journ., 2, p. 586. 1899. — On the presence of members of the diphtheria group of bacilli other than the KLEBSLOEFFLER bac. in milk. Brit. med. Journ., S. 426. 1900. 
FabYan : A contribution to the pathogenesis of bac. abort Bang. Journ. of med. Res. Bd. 26, S. 441. 1912. - A note on the presence of bac. abort. in cows milk. Ebenda, Bd. 28, S. 85-89. 1913. - FadyeaU, M.: Tierärztl. Mitwirkung bei der Milchkontrolle. Zit. nach v. Ostertag. Berlin: R. Schötz. 1926. - FadYeaU und Stockmann: Report of the Departmental Committed appointed by the Board of Agriculture and Fisheries to inquire into epizootic abortion. Journ. of comp. path. a. therap., Bd. 25, S. 22. 1912. - Fauss: Über die Dauer der Ausscheidung von Bakterien bei Mastitis acuta parenchymatosa. Inaug. Diss. Bern. 1909. - FAvILLI: Ricerche e considerazioni critiche sulla febbre mediterranea e sull' aborto epizootico. Sperimentale, 80, H. 1/2, S. 41-76. 1926. - FeInBERG: U̇ber das Verhalten des KLebs-Loefflerschen Diphtheriebazillus in der Milch usw. Zeitschr. f. klin. Med., Bd. 33, S. 432. - FESER: Beobachtungen und Untersuchungen über den Milzbrand. Dtsch. Zeitschr. f. Tiermed. 1880. - Ficker: Typhus und Fliegen. Arch. f. Hyg., Bd. 46, S. 275. 1903. - Fiorentini: La tuberculose mammaire au point de vue de l'infection du lait. L'écho vétér. 1895. - Sulla emolisi dei prodatti sossici del microc. melitense. Lavori Ist. Clin. med., Bd. 28, S. 43 u. 46. Messina. 1907. Fischer: Zur Epidemiologie des Paratyphus. Festschrift f. Koch, S. 271. Jena: G. Fischer. 1903. - Zur Ätiologie der sogenannten Fleischvergiftungen. Zeitschr. f. Hyg. u. Infektionskrankh., Bd. 39, 1902. - FleIschner und MeYER: Preliminary observations on the pathogeni city for monkeys of the Bac. abort. bovin. Transact. of the Americ. ped. soc., XXXII., 141. 1920 u. Zentralbl. f. Bakteriol., Abt. 2, Ref., Bd. 72, S. 367. - Fleischner, Mayer und Shaw: A resume of some experimental studies on cutaneous hypersensitiveness. Americ. journ. of dis. of childr., Bd. 18, S. 577. 1919. - Forster: Über die Beziehungen des Typhus und Paratyphus zu den Gallenwegen. Münch. med. Wochenschr. 1908. - FräNKEL und KüsteR: Über Typhusbazillen in Buttermilch. Münch. med. Wochenschr., S. 197. 1898. - FrIEDRICH: Beiträge zum Verhalten der Cholerabakterien auf Nahrungsund Genußmitteln. Arb. a. d. K. Gesundheitsamte, Bd. 8, S. 465. 1893. - Fröhner: Ein Fall von Übertragung der Aphthenseuche (Maul- und Klauenseuche) vom Rinde auf den Menschen durch Süßbutter. Zeitschr. f. Fleisch- u. Milchhyg., Bd. 1, S. 55.1891 .

Gaethaens: Über die Bedeutung des Vorkommens von Paratyphusbazillen. Arb. a. d. K. Gesundheitsamte, Bd. 25. - Beitrag zur Biologie des Bacillus faecalis alcaligenes. Arch. f. Hyg., Bd. 62. 1907. - Über das Vorkommen von Paratyphusbazillen in Wasser. Arb. a. d. K. Gesundheitsamte, Bd. 30. - GAFFKY: Bericht über die Tätigkeit der zur Erforschung der Cholera im Jahre 1883 entsandten Kommission. Arb. a. d. K. Gesundheitsamte, Bd. 3. 1887. - GärtneR: Über die Fleischvergiftungen in Frankenhausen. Korresp. Blätter des allg. ärztl. Vereins in Breslau. 1888. - GeHrmanN und Evans: Tuberculosis and the tuberculin test by the State Board of live stock commissioners of Illinois, S. 70. Springfield. 1902. Microscopical examination of milk and inoculation experiments. 14. Annual rep. of Illinois state board of live stock commissioners for the year 1899, p. 48-55. Springfield. - Erkrankung an infektiöser Enteritis infolge des Genusses ungekochter Milch. Dtsch. med. Wochenschr., Nr. 14. 1892. - GMINDER: Untersuchungen über Mastitis-Strẹptokokken und ihre Differenzierung von saprophytischen Streptokokken. Zentralbl. f. Bakteriol. usw., Abt. 1, Orig., Bd. 63, S. 152. - Nachweis von Spirillen als Ursache des ansteckenden Verkalbens auch in Deutschland. Berl. Tierärztl. Wochenschr., S. 184. 1922. - GoEBEL: Beitrag zur Frage, welche Organe, Sekrete und Exkrete des kranken Tieres den Maul- und Klauenseucheerreger enthalten. Zeitschr. f. Veterinärkunde, Bd. 34. 1922. - GoRINI: Über die Euterkokken (Mammococcus). Milchwirtschaftl. Forsch., Bd. 3, S. 178. Berlin: Jul. Springer. 1926. - GRÄUB: Infektionen beim Menschen durch den Bazillus des infektiösen Abortus BANG. Schweizer Arch. f. Tierheilk., Bd. 69, S. 394. 1927.

Hastings: Marshalls Microbiology, S. 447. Blakistons Sons and Co. 1911, zit. nach Demeter. - Journ. of Dairy Science. Vol. II, Nr. 4. 1919. - Hastings, Davenport and Wright: Journ. of Dairy Science, Vol. V, Nr. 5. 1922. HAUPT: Zur Frage der Unterscheidung tierpathogener Streptokokken. Dtsch. 
Tierärztl. Wochenschr., S. 607. 1927. - HeIM: Über das Verhalten der Krankheitserreger der Cholera des Unterleibstyphus und der Tuberkulose in Milch, Butter, Molken und Käse. Arb. a. d. K. Gesundheitsamte, 5. Bd. 1889. - Milchsäure- und andere Streptokokken. Zeitschr. f. Hyg. u. Infektionskrankh., 101, S. 104-118. 1923. - Nochmals zur Frage der vermeintlichen Einheit der Streptokokken. Zentralbl. f. Bakteriol. Parasitenk. u. Infektionskrankh., Abt. 1, Orig., Bd. 105, S. 186. 1928. - HeRTwIG: Übertragung tierischer Ansteckungsstoffe auf den Menschen. Med. Ver. Ztg., Nr. 48, S. 226. 1928. - Hesse: Unsere Nahrungsmittel als Nährböden für Typhus und Cholera. Zeitschr. f. Hyg. u. Infektionskrankh., Bd. 5, S. 527. 1889. - Über das Verhalten pathogener Mikroorganismen in pasteurisierter Milch. Zeitschr. f. Hyg. u. Infektionskrankh., Bd. 34, S. 346. 1900. - Hessler: Ein Beitrag zur Frage der Infektiosität der Milch tuberkulöser Kühe. Inaug.-Diss. Bern. 1909. - HeÝmanN: Weitere Beiträge zur Frage über die Beziehungen zwischen Säuglingsernährung und Tuberkulose. Zeitschr. f. Hyg. u. Infektionskrankh., Bd. 60, S. 424. 1908. - HoHN: Die Kultur des Tuberkelbazillus zur Diagnose der Tuberkulose. Münch. med. Wochenschr., S. 609. 1926. - Holst: Om kjedekokker og yverbetaendelser hos kjör som aarsag til akut mavetarmkatarr hos mennesker. Ref. Zentralbl. f. Bakteriol. usw., Abt. 1, Bd. 18. 1111. - HüBener: Paratyphusbazillen und ihnen ähnliche Bakterien bei gesunden Menschen. Zentralbl. f. Bakteriol. usw., Abt. 1, Ref. 1909. - Über das Vorkommen von Bakterien der Paratyphus-B-Gruppe in der Außenwelt. Dtsch. med. Wochenschr., Nr. 24. 1908.

ILkewitsch: Neue Methode zur Entdeckung von Tuberkelbazillen in der Milch mit der Zentrifuge. Münch. med. Wochenschr., S. 69. 1892. - INGHILleRI: Über das Verhalten des Milzbrandbazillus in unsterilisierter Milch. Ref. Zentralbl. f. Bakteriol. usw., S. 820. 1894 .

JAKOBSEN: Verschiedenes aus der Praxis der Fleisch- und Milchkontrolle. Ref. Zeitschr. f. Fleisch- u. Milchhyg., S. 86. 1905. - Die Milchkontrolle der Stadt Kristiania. Zeitschr. f. Fleisch- u. Milchhyg., Bd. 25, H. 6. 1914/15. - JeHLE: Neue Beiträge zur Bakteriologie und Epidemiologie der Ruhr im Kindesalter. Jahrb. f. Kinderheilk., S. 540. 1905. - Jehle und Charleton: Über epidemische und sporadische Ruhr im Kindesalter. Zeitschr. f. Heilk. Inn. Med., Bd. 26, S. 402. 1905. - Jensen, C. 0.: Kälberruhr. Handb. d. pathog. Mirkoorganismen v. Kolle u. WassermanN, Bd. 3. 1903. Jena: G. Fischer. 1902-1904. - Grundriß der Milchkunde. Stuttgart: F. Enke. 1903. - Jensen, ORLA-: Über den Ursprung der Oxydasen und Reduktasen der Kuhmilch. Zentralbl. f. Bakteriol. usw., Abt. 2, Bd. 18, S. 211. 111. - Johannesen: Die epidemische Verbreitung des Scharlachfiebers. Kristiania. 1884. - JoNG: Über Tuberkelbazillen der Milch tuberkulöser Kühe. Zentralbl. f. Bakteriol. usw., Abt. 1, Orig., Bd. 46, S. 213. 1908.

KAISER: Über die Häufigkeit des Streptokokkenbefundes in der Milch. Arch. f. Hyg., Bd. 56, S. 51. - KARLINskr: Eine seltene Darmtyphuskomplikation. Berlin. klin. Wochenschr., S. 866. 1888. - Kitasato: Die Widerstandsfähigkeit der Cholerabazillen gegen Eintrocknen und Hitze. Zeitschr. f. Hyg. u. Infektionskrankh., Bd. 5, S. 134. 1889. - Das Verhalten der Cholerabazillen in Milch. Ebenda. - KleIN, E.: Zur Ätiologie der Diphtherie. Zentralbl. f. Bakteriol. usw., Abt. 1, Orig., Bd. 7. 1890. - Über die Verbreitung des Bacillus enteritidis GäRTNER in der Kuhmilch. Zentralbl. f. Bakteriol. usw., Abt. 1, Orig., Bd. 38, S. 392. 1905. - Ein weiterer Beitrag zur Ätiologie der Diphtherie. Zentralbl. f. Bakteriol. usw., Abt. 1, Orig., Bd. 7, S. 785. 1890. - Klimmer: Untersuchungen über den Keimgehalt der Eselinmilch, über die bakterienvernichtende Eigenschaft usw., Zeitschr. f. Tiermed., Bd. 6. 1902. - Besitzt die unerhitzte Milch bakterizide Eigenschaft? Arch. f. Kinderheilk., Bd. 36, S. 1. 1903. - Klimmer und HaUpt: Beitrag zur Trennung verschiedener tierpathogener und saprophytischer Streptokokken. Zentralbl. f. Bakteriol. usw., Abt. 1, Orig., Bd. 101, S. 126-148. 1927. KLIMmer, HaUPT und Roots: Zur Trennung einiger in der Milch vorkommenden Streptokokken mit besonderer Berücksichtigung der Isolierung des Str. agalact. 
Quillebeau. Zentralbl. f. Bakteriol. usw., Abt. I, Orig., Bd. 107, S. 206. 1928. KNÜPPEL: Die Erfahrungen der englisch-ostindischen Ärzte betreffs der Choleraätiologie usw. Zeitschr. f. Hyg. u. Infektionskrankh., Bd. 10. 1891. - KoCH: Tuberkulosenkongreß London. 1901. - Koestler, Steck und RadosavlJevitch: Störungen in der Milchbildung und ihr Zusammenhang mit der natürlichen Bakterien. besiedlung des Euters. Zentralbl. f. Bakteriol. usw., Abt. 2, Bd. 57. - Kolle: Milchhygienische Untersuchungen. Klin. Jahrb., Bd. 13. 1905. - KonING: Biologische und biochemische Studien über Milch. Milchwirtschaftl. Zentralbl. 1905 u. 1906. - Kossex: Zur Verbreitung des Typhus der Bazillenträger. Dtsch. med. Wochenschr., S. 1584. 1907. - Übertragung der Cholera asiatica durch Lebensmittel. Dtsch. med. Wochenschr., S. 1024. 1892. - Vergleichende Untersuchungen über Tuberkelbazillen verschiedener Herkunft. Tuberkul. Arb. a. d. K. Gesundheitsamte. $1904 \mathrm{u}$. 1905. - KraJEwSKY : Über Maul- und Klauenseuche bei Haustieren und ihr Übergehen auf den Menschen. Przeglad Weterynarski, Nr. 3. 1901.

LAMERIS und v. HARREveld: Bakterienfund in Kuhmilch nach abgeheilter Mastitis. Zit. nach Ref. Zentralbl. f. Bakteriol. usw., Bd. 30, S. 83. - LASER: Über das Verhalten von Typhusbazillen, Cholerabakterien und Tuberkelbazillen in Butter. Zeitschr. f. Hyg. u. Infektionskrankh., Bd. 10, S. 513. 1891. - LIMoN: Über Bakterien am und im Euter. Inaug.-Diss. Erlangen. 1898. - Lister: Transactions of the Patholog. Soc. of London, Vol. XXIX, p. 425. - LöfFler: Hygiene der Molkereiprodukte. Dtsch. med. Wochenschr., S. 885. 1901. - Lumsden, RosenAU und CASTLE: Report on the origin and prevalence of typhoid fever in the district of Columbia Treasury Departm. Bull., Nr. 35. 1907 u. Nr. 44. 1908. - LÜTJE: Paratyphuserkrankungen, verursacht durch das Bacterium enteritidis GÄRTNER bei erwachsenen Rindern. Dtsch. Tierärztl. Wochenschr., S. 34. 1926. - LuX: Über den Gehalt der frisch gemolkenen Milch an Bakterien. Zentralbl. f. Bakteriol. usw., Orig., Abt. 2. Bd. 11. 1111. - Lzasz: Über den Bakteriengehalt der Milch. Dtsch. Tierärztl. Wochenschr., S. 462. 1906.

Marshall: Note on the occurrence of diphtheria bacilli in milk. The Journ. of Hygien. V., Bd. 7, Nr. 1, S. 32. 1907. - MoHLER: Infectiveness of milk of cows which have reacted to ble tuberculin test. U. S. Dep. of Agricult, Bureau of animal industry. Bull., Nr. 44. Washington. 1903. - MonatzKow: Über Veränderung der Milch bei Impfmilzbrand. Petersburg. 1881. - Montefusco: Del modo di comportarsi del bacillo della difterite sulle sostanze alimentari. Ann. D'Igien. sperim., Vol. VI, p. 425. 1896. - Monvorsin: Le lait. Paris. 1920. Moussu: Le lait des vaches tuberculeuses. Compt. rend. de la Soc. de Biol., S. 617. 1904. - Ref. Die Milch tuberkulöser Kühe. Arch. f. wissensch. u. prakt. Tierheilk., Bd. 32, S. 279. 1906. - MÜLLER: Milch und Molkereiprodukte als Verbreiter der Tuberkulose. Bericht d. internat. tierärztl. Kong., Bd. 2, S. 175. Müller, Lindemann und Lange: Bericht über die Maßnahmen der ostpreußischen Holländer Herdbuchgesellschaft zur Bekämpfung der Rindertuberkulose. Berlin. Tierärztl. Wochenschr. 1902.

OBERMÜLLER: Über neuere Untersuchungen, das Vorkommen echter Tuberkelbazillen in der Milch usw. Hyg. Rundschau, 10. Jahrg., S. 845. 1900. - OsterTAG, v.: Tierärztliche Mitwirkung bei der Milchkontrolle. Berlin: R. Schötz. 1926. - Handbuch der Fleischbeschau, 4. Aufl., S. 237. Stuttgart: F. Enke. 1902. Untersuchungen über den Tuberkelbazillengehalt der Milch von Kühen, welche auf Tuberkulin reagiert haben, klinische Erscheinungen der Tuberkulose aber noch nicht zeigten. Zeitschr. f. Hyg. u. Infektionskrankh. d. Haustiere, Bd. 38, S. 415. 1913. - Weitere Untersuchungen usw. Zeitschr. f. Fleisch- u. Milchhyg., Bd. 9, S. 168 u. 221, u. Bd. 12, S. 1, 72 u. 109. - Die Bekämpfung der Tuberkulose. Berlin: Rich. Schötz. 1913. - Ostertag, Breidert, Kaestner und Krautstrunk: Untersuchungen über die klinische und bakteriologische Feststellung der Tuberkulose des Rindes. V. Arbeit aus dem Hyg. Institut d. Tierärztl. Hochschule Berlin.

PaPe: Ein Beitrag zur Maul- und Klauenseuche des Menschen. Berlin. Tierärztl. Wochenschr., S. 245. 1921. - PetrI: Zum Nachweis der Tuberkelbazillen in Butter und Milch. Arb. a. d. K. Gesundheitsamte, Bd. 14. 1897/98. — PFuHL: 
Vergleichende Untersuchungen über die Haltbarkeit der Ruhrbazillen und der Typhusbazillen außerhalb des menschlichen Körpers. Zeitschr. f. Hyg., Bd. 40. 1902. - PopPe: Die BANG-Infektion des Menschen. Dtsch. Tierärztl. Wochenschr. 36. Jahrg., S. 781. 1928. - Die Berufsinfektionen des Tierarztes. Tierärztl. Rundschau, S. 293. 1920. - PröschOLD: Die Bekämpfung der Geflügeltuberkulose unter Zuhilfenahme der Intrakutanimpfung zur Feststellung der tuberkulösen Kühe. Berlin. tierärztl. Wochenschr., S. 553. 1921. - Impfversuche an Meerschweinchen und Fütterungsversuche an Schweinen zur Prüfung der Zuverlässigkeit der Dauerhitzung usw. Arch. f. wissenschaftl. u. prakt. Tierheilk., Bd. 58, S. 297.1928.

Ravenel: Transactions of the British Congress of Tuberculosis, Bd. 3. 1901. Ref. Zeitschr. f. Tiermed., Bd. 8. S. 208. - Rowland: Cheese and butter as possible carriers of typhoid and cholera infection. British med. journ., Vol. 1, S. 1392. - Rubinowitsch: Über Tuberkelbazillen in Milch und Molkereiprodukten. Zeitschr. f. Untersuch. d. Nahrungs- u. Genußmittel, S. 810. 1900. - Zur Frage der Infektiosität der Milch tuberkulöser Kühe. Zeitschr. f. Tiermed., Bd. 8, S. 202. - Beitrag zur Frage der Infektiosität der Milch tuberkulöser Kühe sowie über den Nutzen der Tuberkulinimpfung. Zeitschr. f. Hyg. u. Infektionskrankh., Bd. 31, S. 137. - Verhandlungen der 78. Versammlung deutscher Naturforscher und Ärzte, II. Teil, 2. Hälfte, S. 364. Stuttgart. 1906. - RUdoLF: Über das Verhalten verschiedener tierischer Streptokokken in der Lackmusmilch unter besonderer Berücksichtigung des Streptococcus mastitidis und Streptococcus lactis. Zentralbl. f. Bakteriol. usw., Abt. 1, Orig., Bd. 100, S. 47, 61. - Beitrag zur Morphologie und Biologie des Galtstreptokokkus. Ebenda, Bd. 98, S. 47.

SANDE, v.: Die Veränderung der Lackmusmilch durch Streptokokken. Dtsch. tierärztl. Wochenschr., S. 329. 1927. - SCHELlER: Beiträge zur Typhusepidemiologie. Zentralbl. f. Bakteriol. usw., Abt. 1, Orig., Bd. 46, S. 385. 1908 SCHEURLEN: Über die Wirkung des Zentrifugierens, besonders auf die Verteilung der Bakterien in der Milch. Arb. a. d. K. Gesundheitsamte, Bd. 7, S. 2 u. 3. 1891. - Schmit und Pröschold: Über die Verwendbarkeit des Antiformins zum Nachweis der offenen Formen der Rindertuberkulose. Zeitschr. f. Hyg. u. Infektionskrankh. d. Haustiere, Bd. 11. 1912. - SCHNEIDER: Erfahrungen über die Maul- und Klauenseuche. Zit. nach Baum. Arch. f. wissenschaftl. u. prakt. Tierheilkunde. - SchоттELIUS: Über das Wachstum der Diphtheriebazillen in Milch. Zentralbl. f. Bakteriol. usw., Abt. 1, Bd. 20, S. 897. 1896. — SсноттMÜLLER: Die Artunterscheidung der für die Menschen pathogenen Streptokokken durch Blutagar. Münch. med. Wochenschr., Nr. 20 u. 21. 1903. - ScHÜDER: Zur Ätiologie des Typhus. Zeitschr. f. Hyg. u. Infektionskrankh., Bd. 38., S. 343. 1901. - Schrank: Über das Verhalten der Cholerabakterien in einigen Nahrungsund Genußmitteln. Zeitschr. d. allg. österr. Apothekervereines, Nr. 1, S. 5. 1895. - SCHRöDER: Further experimental observations on the presence of tub. bac. in the milk of cows. U. S. Dep. of agriculture, Bureau of animal industry. Bull. 7, S. 75. - Schulz: Über den Schmutzgehalt der Würzburger Marktmilch und die Herkunft der Milchbakterien. Arch. f. Hygiene, Bd. 14, S. 260. - SeelemanN: Untersuchungen über die Sekretionsstörungen der Milchdrüse usw. Arch. f. wissenschaftl. u. prakt. Tierheilk., Bd. 58, S. 1. 1928 . Weitere Untersuchungen über die Zuverlässigkeit der Dauer- und Hochpasteurisierung der Milch zwecks Abtötung von Tuberkelbazillen. Dtsch. Tierärztl. Wochenschr., 35. Jahrg., S. 765-770. 1927. - SeElemanN und Klingmüller: Die Züchtung von Tuberkelbakterien aus verschiedenen Ausgangsmaterialien mit Hilfe des sogenannten Säurebehandlungsverfahrens. Zentralbl. f. Bakteriol. usw., Abt. 1, Orig., Bd. 104, S. 483. 1927. - Über die Widerstandskraft der Bakterien der Typhus-Paratyphus-Gruppe in dauererhitzter Milch. Zeitschr. f. Fleisch- u. Milchhyg., Bd. 36, S. 250. 1926. — SeligmanN: Zur Biologie der Kuhmilch. Zeitschr. f. Hygiene u. Infektionskrankh., Bd. 88, S. 333. - SHERmann and Albus: Journ. of Bacteriol., 3, 153, zit. nach Demeter. - Sievering: Welche Rolle spielt die Milch bei der Verbreitung von Typhus, Diphtherie und Scharlach? Die Milch 
und ihre Bedeutung für Volkswirtschaft und Volksgesundheit. Hamburg: C. Boysen. 1903. - Simpson: Report on the butbreak of cholera usw. Veröffentl. d. K. Gesundheitsamtes, S. 494. 1888. - SkaR, O.: Nachweis und Bekämpfung der Euterentzündung beim Rinde. Zeitschr. f. Infektionskrankh., parasitäre Krankh. u. Hyg. d. Haustiere, 34. Bd., S. 385. 1908. - SмIth und FabIaN: Über die pathogene Wirkung des Bacillus abortus BANG. Zentralbl. f. Bakteriol. usw., Abt. 1, Orig., Bd. 61, S. 549. 1912. - SOMMERFELD: Beitrag zur katalysierenden Eigenschaft der Milch. Zeitschr. f. Fleisch- u. Milchhyg., S. 105. 1908. - Handbuch der Milchkunde. Wiesbaden: J. F. Bergmann. 1909. - Standfuss: Bakteriologische Fleischbeschau. Berlin: R. Schötz. 1928. - SтесK, W.: Beiträge zur Kenntnis der Bakterienansiedlung in normalen Kuheutern. Schweizer Zentralbl. f. Milchwirtschaft, Nr. 38 u. 39. 1920, ferner Schweizer Arch. f. Tierheilk., Bd. 62, S. 525. - Untersuchungen über bakterielle Besiedelung normaler Kuheuter. Landwirtschaftl. Jahrbuch der Schweiz, S. 511. 1921. - SteInerT: Zur Frage: Ist der Bacillus abortus BANG für Menschen pathogen? Münch. Tierärztl. Wochenschr., 77. Jahrg., S. 63. 1926. - Stenström: Beitrag zur Frage über das Vorkommen von Tuberkelbazillen in der Milch reagierender Kühe. Zeitschr. f. Tiermed., Bd. 6., S. 241.

Trtze: Die Ätiologie der Kälberruhr. Zentralbl. f. Bakteriol. usw., Abt. 1, Ref., Bd. 42, Beiheft, S. 139. 1908. - THÖRNER: Tuberkulosennachweis. Milchzeitung, 1156. 1891. - Trask: Milk as a cause of epidemics of typhoid fever, scarlet fever and diphtheria. Hygienic. Laborat. Bull., Nr. 41, S. 21, Washington. 1908.

Uhlenhuth: Zur Kenntnis der gastrointestinalen Fleischvergiftung und der biologischen Eigenschaften ihrer Erreger. Gedenkschrift f. R. v. LEUTHOLD, Bd. 1. 1906. - Uhlenhuth und HÜBener: Über die Verbreitung der Bakterien der Paratyphus-B- und Gärtner-Gruppe und ihre Beziehungen zur gastrointestinalen Form der Fleischvergiftungen. Zentralbl. f. Bakteriol. usw., Abt. 1, Orig. 1908. - Bericht über die Tagung der freien Vereinigung f. Mikrobiologie, Beilage zu Abt. 1, Bd. 42. 1908.

VAGEDES, v.: Paratyphusbazillen und Mehlspeisenvergiftung. Klin. Jahrb., Bd. 14, S. 517, 1905. - VANDEvelde, DE WAELe und SugG: Ưber proteolytische Enzyme der Milch. Hofmeisters Beiträge zum chem. Physiol. und Pathol. Bd. 5, S. 571. 1804. - Vercellana und Zanzucchi: Pathologica Jahrbuch, 18, S. 247. 1926. - Vieth: Die Verbreitung ansteckender Krankheiten durch Milch. Milchzeitung, S. 569. 1886 .

Wall, Sv.: Die Euterentzündungen. Stuttgart: F. Enke. 1908. - Weber und Titze: Die Immunisierung der Rinder gegen Tuberkulose. Tub. Arb. a. d. ReichsGesundheitsamte. 1908. - Weitere Passagenversuche mit Bazillen des Typus humanus. Fütterungsversuche mit Hühnertuberkulosebazillen an Schweinen und an einem Fohlen. Tub. Arb. a. d. K. Gesundheitsamte, 7., 9., 10. H. 1907. - Die Immunisierung der Rinder gegen Tuberkulose. Versuche über die "Haltbarkeit der behufs Immunisierung eingespritzten menschlichen Tuberkelbazillen im Körper des Rindes. Ausscheidung von Tuberkelbazillen mit der Kuhmilch nach intravenöser Injektion menschlicher Tuberkelbazillen. Tub. Arb. a. d. K. Gesundheitsamte, 9. H. 1908. - WedemanN: Der Einfluß der Milchsäuregärung auf in Milch enthaltene pathogene Keime. Zentralbl. f. Bakteriol. usw., Abt. 1, Orig., 97. Bd., Beiheft. 1926. - WEICHEL und ZwICK: Bakteriologische Untersuchungen über die Erreger der Mastitis acuta des Rindes mit besonderer Berücksichtigung der Beteiligung von sogenannten Fleischvergiftungserregern an der Entstehung der Krankheit. Arb. a. d. Reichs-Gesundheitsamte, Bd. 33, S. 250. 1910. - Weigmann, Gruber, Huss: Über armenisches Mazun. Zentralbl. f. Bakteriol. usw., Abt. 2, Bd. 19, S. 70. 1908. - Weigmann und ZIRN: Über das Verhalten der Cholerabakterien in Milch und Molkereiprodukten. Zentralbl. f. Bakteriol. usw., Abt. 1, Orig., Bd. 15, S. 286. 1894. - WeYrauch: Ein Fall von Maltafieber in Jena. Münch. med. Wochenschr. 73, S. 321. 1926. - WLAdimiroff: Contribution à l'étude du rôle du lait dans l'étiologie de la diphtherie. Arch. des science biol. Petersburg. 1895. - WohlfeIL: Zur Methodik des Typhusbazillennachweises in der Milch. Zentralbl. f. Bakteriol. usw., Abt. 1, Orig., Bd. 101, S. 311. 1927. 
Zangemeister: Über die Verbreitung der Streptokokken im Hinblick auf ihre Infektiosität und ihre hämolytische Eigenschaft. Münch. med. Wochenschr. 1910. ZARIBNICKY: Über den Einfluß von Krankheiten der Rinder auf die Milch. Arch. f. wissenschaftl. u. prakt. Tierheilk., S. 355. 1914. - Die tierärztliche Kontrolle in Vorzugsmilchstallungen. Wien. Tierärztl. Monatsschr., 14. Jahrg., 8. H. 1927. Beiträge zu chemischen Leistungen einiger in der Milch vorkommenden Bakterien. Milchwirtschaftl. Forsch., Bd. 3., S. 432 u. Bd. 5, S. 361. - ZaRniko: Zur Kenntnis des Diphtheriebazillus. Zentralbl. f. Bakteriol. usw., Abt. 1, Bd. 6. 1889. Zeller: Über den infektiösen Abortus des Rindes. Berl. tierärztl. Wochenschr. S. 645. 1913. - Beziehungen zwischen dem Erreger des infektiösen Abortus der Rinder und des Maltafiebers. Berlin. Tierärztl. Wochenschr., S. 345. 1920. Weitere Untersuchungen über das seuchenhafte Verwerfen des Rindes. Arch. f. wissenschaftl. u. prakt. Tierheilk., Bd. 49, S. 65. 1922. - Seuchenhafter Abortus. AbDerhaldens Handbuch der biologischen Arbeitsmethoden, XIII, S. 269. 1921. - Differenzierungsversuche in der Paratyphus-GÄRTNER-Gruppe. Zeitschr. f. Infektionskrankh. d. Haustiere, 23, s. 191. 1922. J. 191. - ZwICK: Vergleichende Untersuchungen über die Tuberkelbazillen des Menschen und der Haustiere. Zeitschr. f. Infektionskrankh. d. Haustiere, S. 161. - ZwICK und KRAGE: Über die Ausscheidung von Abortusbazillen mit der Milch infizierter Tiere. Berlin. Tierärztl. Wochenschr., Bd. 29, S. 41. - ZwICK und WeICHeL: Bakteriologische Untersuchungen über die Erreger der Mastitis acuta des Rindes mit besonderer Berücksichtigung der Beteiligung von sogenannten Fleischvergiftungserregern an der Entstehung der Krankheit. Arb. a. d. K. Gesundheitsamte, Bd. 34, S. 391 1910. - ZwICK und ZeLler: Über den infektiösen Abortus des Rindes. Arb. a. d. K. Gesundheitsamte, Bd. 43, S. 1. 1913. - ZwICK und Zeller, Krage und GMINDER: Die Immunisierung gegen das ansteckende Verkalben. Arb. a. d. ReichsGesundheitsamte, Bd. 52, S. 375. 1921.

\section{Sammelwerke:}

ERNST: Grundriß der Milchhygiene. Stuttgart: F. Enke. 1926.

GrIMMER: Milchwirtschaftliches Praktikum. Leipzig: Akad. Verlagsges. Leipzig: 1926. - Chemie und Physiologie der Milch. Berlin: Paul Parey. Berlin. 1910.

Orla-Jensen: Die Bakteriologie in der Milchwirtschaft. Jena: Gustav Fischer. 1913.

Rievel: Handbuch der Milchkunde. Hannover: V. Schaper. 1910. - Rubner, GrUBER, Ficker: Handbuch der Hygiene. Leipzig: Hirzel. 1911-1913.

Sommerfeld: Handbuch der Milchkunde. Wiesbaden: J. F. Bergmann. 1909. 